\title{
Experimental and numerical characterization of food dehydration during freezing
}

\section{Violette MULOT $^{(a, b, c)}$, Hayat BENKHELIFA ${ }^{(a, b)}$, Didier PATHIER ${ }^{(\mathrm{c})}$, Fatou-Toutie NDOYE ${ }^{(a)}$, Denis FLICK ${ }^{(a, b)}$}

\author{
${ }^{(a)}$ IRSTEA, Génie des Procédés Frigorifiques (GPAN) \\ Antony, F-92160, France \\ (b) AgroParisTech, Inra, Université Paris-Saclay, \\ UMR Ingénierie, Procédés, Aliments (GENIAL) \\ Massy, F-91300, France, denis.flick@agroparistech.fr \\ ${ }^{(c)}$ Air Liquide, Paris Innovation campus \\ Jouy-en-Josas, F-78350, France
}

\begin{abstract}
Using freezing in industry means understanding and controlling the process, particularly in terms of heat and water transfers. Water transfer is responsible for food dehydration during freezing which represents weight losses up to $6 \%$ according to the product characteristics and the freezing process. A model of heat and mass transfer during the freezing process was developed. It takes into account not only heat transfer and crystallization but also water transfer, evaporation and sublimation. A methodology was established to identify some important and correlated model parameters: water activity, initial freezing temperature and ice fraction from the enthalpy-temperature curve of a product. The model allows predicting the freezing time and weight loss for a given non-porous product (initial temperature, composition, geometry, dimensions, and physical properties) and a given freezing process (temperature, hygrometry, convective heat transfer coefficient). The numerical results were compared with experimental data obtained with Tylose in a pilot plant freezer from $-30^{\circ} \mathrm{C}$ to $-100^{\circ} \mathrm{C}$.
\end{abstract}

Keywords: Model; food dehydration; weight loss; freezing.

\section{INTRODUCTION}

Freezing is an essential process in food preservation. It guarantees long preservation with relatively low impact on product quality. Freezing consists in reducing a product temperature below its freezing point in order to solidify a portion of its water. The water state change is the core of the freezing process because it decreases water activity which means water availability, thus, limiting the development of micro-organisms. Two types of transfers occur during the freezing of unwrapped products:

- Heat transfer: the product in contact with cold air releases energy to the surrounding environment. This leads to a temperature gradient in the product inducing a conductive heat transfer from the core to the surface and phase change (water crystallization) until reaching thermal equilibrium.

- Water transfer: the water vapor concentration in the surrounding air is lower than the water 
vapor concentration in the air in equilibrium with the product surface. Thus, a water transfer occurs between the product and its surroundings. As for heat transfer, a water concentration gradient appears in the product inducing a diffusive water transfer from the core to the surface and then to the surroundings where, during the pre-cooling stage, water evaporates from the surface. When ice is formed from the product surface, water diffusion is only significant in the non-frozen part of the product and ice sublimates from the surface causing the emergence of a dehydrated layer like in freeze-drying.

Water transfer induces food dehydration decreasing frozen food quality and weight. The weight loss depends on the product characteristics and the freezing process which represents both quality and financial losses.

Predictive models of freezing time and weight loss according to a product and a freezing process are useful tools. These models are developed from heat and mass transfer balances at unsteady state. These balances are coupled because of phase changes at the product surface: water evaporation and ice sublimation

Analytical solving of transfer equations is very complex and supposes many simplifying assumptions. Indeed, heat transfer in the product is mainly conductive and the temperature gradient is the driving force, thereby Fourier's law is considered. Water transfer is essentially diffusive and the water concentration gradient in the product is the driving force. Fick's law is thus considered for water transfer.

Moreover, crystallization implies complexity in the solving of the heat transfer equation because of:

- A discontinuity zone at the interface between liquid and solid phase which leads to a sudden variation of food thermo-physical properties.

- A high amount of heat released due to the solidification of water (latent heat of solidification). Numerical methods are usually chosen to solve the partial derivative equations of heat and water transfer during freezing. Many numerical models for prediction of freezing time and weight loss were developed, different from each other by the transfer hypotheses and the type of product. For discretization in time: either explicit (Tocci and Mascheroni, 1995), implicit (Campañone et al., 1998) or Crank-Nicolson methods (Campañone et al., 2001) were used. For discretization in space, various methods exist (Pham, 2006) : the finite difference method (Campañone et al., 2001; Campañone et al., 1998; Tocci and Mascheroni, 1995), the finite volume method (Pham, 2014) and the finite element method.

Campañone et al. (2001) numerically solved transfer equations for two freezing stages considering 1D transfers, and food with regular shapes:

- The first freezing stage corresponds to the pre-cooling of the product surface from the initial temperature to the initial freezing temperature. During this stage, water diffuses from the product core to the surface where it evaporates.

- The second freezing stage occurs after the surface began freezing. A freezing front moves towards the thermal center. The product is divided into three zones: unfrozen, partially frozen and dehydrated. Water does not diffuse anymore through the product but ice starts sublimating from the surface to the surroundings creating a dehydrated layer with a sublimation front 
moving to the product thermal center. Some other numerical models were developed (Andreasen, 2009; Campañone et al., 2005a; Pham, 2006; Pham and Willix, 1984) with some differences in the assumptions. For example, Campañone et al. (2001) mentioned an ice fraction adsorbed by the product matrix that could not sublimate whereas Andreasen (2009) did not.

Once they are established, models are validated with experimental data of freezing time and weight loss during freezing. Meat and fish products were widely studied (Boonsumrej et al., 2007; Bustabad, 1999; Campanone et al., 2002; Espinoza Rodezno et al., 2013; Lambrinos and Aguirre-Puente, 2003; Pham and Willix, 1984). Fewer studies focus on highly porous products like pre-baked bread (Hamdami et al., 2004a, 2004b).

From validated numerical models, simplified ones were also proposed (Campañone et al., 2001). All these models are decision tools for selecting one technology (characterized by the ranges of temperature and air velocity) relatively to another one in order to freeze a given product and limit the weight loss.

Numerical parametric analyzes permit to point out the influence of the freezing process parameters (temperature from $-9^{\circ} \mathrm{C}$ to $-45^{\circ} \mathrm{C}$, flow velocity from 0.5 to $2.5 \mathrm{~m} \mathrm{~s}^{-1}$ and hygrometry from 40 to $52 \%$ ) on the weight loss and freezing time for a given product (Campañone et al., 2001; Campañone et al., 1998).

The aim of the present work is to develop a numerical model of heat and mass transfers in non-porous food during freezing. This model links three fundamental variables thanks to water phase diagram: water activity, initial freezing temperature and ice content. Only three parameters are necessary to predict all these variables and they are solely determined from the enthalpy curve Results of freezing time and weight loss obtained with the numerical model were compared with data from experiments with Tylose. Tylose has a constant composition and can be used as a beef meat model material for heat transfer although this is not really the case for mass transfer (meat membranes and fat layers are barriers for mass transfer which are not present in Tylose). These comparisons are presented for different freezing conditions not only in the mechanical cold domain $\left(-30^{\circ} \mathrm{C},-50^{\circ} \mathrm{C}\right)$ but also in the cryogenic freezing field $\left(-100^{\circ} \mathrm{C}\right)$.

\section{MATERIALS AND METHODS}

\subsection{Experimental work}

\subsubsection{Freezing equipment}

A freezing cabinet (Figure 1) was designed and developed for these experiments. It is able to recreate both mechanical and cryogenic freezing conditions in terms of temperature and gas flow velocity (Mulot et al., 2018). It consists of a closed cabinet where the cold flow is conducted through a $2.8 \mathrm{~m}$ long duct equipped with some perforated grids to homogenize it. Temperature is adjustable from room temperature to $-100^{\circ} \mathrm{C}$ using a nitrogen injection and the gas flow velocity is adjustable from 0 to $9 \mathrm{~m} \mathrm{~s}^{-}$ 
1 thanks to a variable frequency fan. In the measuring zone, where samples are located, some preliminary measurements were made to validate the uniformity of temperature, gas flow velocity and convective heat transfer coefficient. A special device was used to estimate the convective heat transfer coefficients $(h)$ at mid-height of the measuring zone. This device is composed of a copper plate $(50 \times 50$ $\mathrm{mm}$ ) which is heated by an electrical resistance and insulated underneath. Two type-T thermocouples measure the temperature of the copper surface and the gas temperature above it. A programmable controller performs temperature recording and flux calculation.

It permitted to establish the correlation between Nusselt $(\mathrm{Nu})$, Reynolds $(\mathrm{Re})$ and Prandtl $(\mathrm{Pr})$ numbers characterizing the flow around plates in the measuring zone. Three flow velocities were studied: 4.2, 6.6 and $8.4 \mathrm{~m} \mathrm{~s}^{-1}$ for four temperature set points: $15^{\circ} \mathrm{C},-30^{\circ} \mathrm{C},-50^{\circ} \mathrm{C}$ and $-100^{\circ} \mathrm{C}$. Heat transfer coefficients were recorded for $120 \mathrm{~s}$ once the freezing cabinet was stabilized. From these results (Table 1 ), the convective heat transfer coefficient $(h)$ as a function of temperature $\left(T_{g}\right)$ and gas flow velocity $\left(v_{s}\right)$ was deduced (Equation 1).

$$
\mathrm{Nu}=\frac{\mathrm{hL}}{\mathrm{k}_{\mathrm{g}\left(\mathrm{T}_{\mathrm{g}}\right)}}=0.066 \operatorname{Re}_{\left(\mathrm{T}_{\left.\mathrm{g}, \mathrm{v}_{\mathrm{s}}\right)}\right.}{ }^{0.80} \operatorname{Pr}_{\left(\mathrm{T}_{\mathrm{g}}\right)}{ }^{1 / 3}
$$

where $k_{g}$ is the gas thermal conductivity and $L$ the length of the sample (plate) placed in the freezing cabinet $(\mathrm{L}=80 \mathrm{~mm})$.

\subsubsection{Sample characteristics}

Tylose plates were used (length $=80 \mathrm{~mm}$, width $=50 \mathrm{~mm}$, thickness $=18 \mathrm{~mm}$, mass=70.7-73.8 $\mathrm{g}$ ). Their lateral faces were insulated with expanded polystyrene in order to consider only 1D heat and mass transfer (vertically, throughout the thickness of the product).

Sample initial temperature was uniform and was $20^{\circ} \mathrm{C}$. Three samples were placed per freezing run in the freezing cabinet. One was dedicated to the sample core and surface temperature recording: two calibrated type-T thermocouples (precision $0.1^{\circ} \mathrm{C}$ ) were inserted into a needle so that they could be accurately positioned at the sample core and just under the surface. The other two samples were dedicated to weight recording. Two scales were used: Mettler Toledo ${ }^{\circledR}$ PG1003S and Sartorius ${ }^{\circledR}$ QUINTIX3102-1S with a weighing precision of 0.01g. Scales were fitted with hangers for below-thebalance weighing. Thus, scales were kept outside the freezing cabinet while samples were in the cold zone.

\subsubsection{Experimental procedure}

Six freezing operating conditions were studied, three temperatures: $-30^{\circ} \mathrm{C},-50^{\circ} \mathrm{C}$ and $-100^{\circ} \mathrm{C}$ and two gas flow velocities: $3.9 \mathrm{~m} \mathrm{~s}^{-1}$ and $7.7 \mathrm{~m} \mathrm{~s}^{-1}$.

The freezing time was defined as the time required for thermal center of Tylose samples to reach $18^{\circ} \mathrm{C}$.

Two types of experimental work were carried out:

- Firstly, Tylose dehydration due to freezing process was studied by measuring the total weight loss. Three replicates were made for each operating condition. Once the steady state was 
reached inside the freezing cabinet, process ventilation and nitrogen injection were switched off and samples were introduced in the freezing cabinet. The initial masses of samples suspended inside the cabinet were measured. Then, process ventilation and nitrogen injection were switched on until reaching the reference freezing time previously determined. At the end of freezing time, the freezing cabinet was switched off and the final masses of samples suspended inside the freezing cabinet were measured.

- Secondly, Tylose dehydration kinetics during freezing was studied by measuring weight loss at regular time steps for one freezing operating condition: $-30^{\circ} \mathrm{C} / 3.9 \mathrm{~m} \mathrm{~s}^{-1}$ ( 3 replicates). The protocol is similar to the previous one. However, four intermediate weighing were performed: after 5, 10, 15, 30 and 45 minutes of freezing.

\subsection{Modeling}

A model was developed to predict heat and mass transfers in a non-porous food during freezing. This model assumes no change of density and size of food between the fresh and frozen state.

\subsubsection{Water and heat transfer assumptions}

Freezing can be considered like a succession of several periods.

The first step is the pre-cooling stage: the surface product temperature decreases from the initial temperature to the initial freezing temperature. Water is in liquid form and diffuses from the product core to the surface where it evaporates towards the outside environment. Heat is conducted throughout the product from the thermal center to the surface where it is partially released by convection in the environment and partially used for water evaporation. These heat and water transfer phenomena are represented in Figure 2a.

When product surface starts freezing, the second freezing step begins: water starts solidifying. Product is divided into three zones (Figure $2 b$ ):

- The first zone is the unfrozen zone (zone 1) where water has not begun freezing because temperature has not reached the initial freezing temperature. In this zone, water keeps diffusing from the core to the freezing front.

- The second zone from the freezing front to the sublimation front is the partially frozen zone (zone 2). The freezing front moves towards the thermal center of the product increasing the frozen part. It is assumed that water diffusion does not occur anymore in this zone because the ice crystal network hinders water migration.

- The third zone is a small dehydrated layer (zone 3) at the product surface due to ice sublimation. A sublimation front is slowly moving from the surface to the freezing front: ice crystals sublimation creates a porous dehydrated layer. In this dehydrated layer, water vapor diffuses through the air inside the pores until the product surface.

\subsubsection{Water and heat transfer equations}

Water transfer is essentially diffusive in the non-frozen part of the product, the driving force is the water concentration gradient in the product. Fick's law is considered for unidimensional water transfer 
(Equation 2).

$$
\begin{aligned}
& \frac{\partial \mathrm{C}_{\mathrm{w}}}{\partial \mathrm{t}}=\frac{1}{\mathrm{x}^{\alpha}} \frac{\partial}{\partial \mathrm{x}}\left(\mathrm{x}^{\alpha} \mathrm{D}_{\mathrm{w}} \frac{\partial \mathrm{C}_{\mathrm{w}}}{\partial \mathrm{x}}\right) \\
& \text { With } \quad \mathrm{C}_{\mathrm{w}}=\mathrm{C}_{\mathrm{dm}} \mathrm{Y}_{\mathrm{w}}
\end{aligned}
$$

where $C_{w}$ is the water mass concentration, $\mathrm{t}$ is time, $x$ is the location in the product, $D_{w}$ is the water diffusivity and $\alpha$ is the geometric factor $(\alpha=0$ for an infinite plate, $\alpha=1$ for a cylinder and $\alpha=2$ in case of a sphere). Finally, $C_{d m}$ is the dry matter concentration and $Y_{w}$ is the liquid water content in the product expressed on a dry basis. In the frozen part, it is considered that water does not diffuse anymore. In the dehydrated layer, water vapor diffuses from the sublimation front to the surface.

Heat transfer in the product is mainly conductive, the driving force is the temperature gradient. Fourier's law for unidimensional heat transfer is used (Equation 3), considering that heat transfer by water diffusion is negligible.

$$
\begin{aligned}
\rho \mathrm{Cp}_{\mathrm{app}} \frac{\partial \mathrm{T}}{\partial \mathrm{t}} & =\frac{1}{\mathrm{x}^{\alpha}} \frac{\partial}{\partial \mathrm{x}}\left(\mathrm{x}^{\alpha} \mathrm{k} \frac{\partial \mathrm{T}}{\partial \mathrm{x}}\right) \\
\text { With } \rho \mathrm{Cp}_{\mathrm{app}} & =\rho \mathrm{Cp}-\mathrm{C}_{\mathrm{dm}} \mathrm{L}_{\mathrm{f}} \frac{d Y_{i}}{d T}
\end{aligned}
$$

where $\rho$ is the density, $C p_{a p p}$ is the apparent mass specific heat capacity, $k$ is the product thermal conductivity, $\mathrm{T}$ is the product temperature, $C p$ is the mass specific heat capacity, $L_{f}$ the latent heat of fusion and $Y_{i}$ the ice fraction in the product (dry basis).

\subsubsection{Boundary conditions}

\section{Symmetry}

As symmetrical shapes are considered for the products, the liquid water concentration gradient and the temperature gradient are zero at the symmetry axis or plan (Equation 4 and Equation 5).

$$
\begin{aligned}
& \frac{\partial C_{w}}{\partial x}=0 \\
& \frac{\partial T}{\partial x}=0
\end{aligned}
$$

\section{Surface and sublimation front}

During the pre-cooling stage, product surface is not frozen yet, the difference between the water vapor concentration in equilibrium with product surface $\left(C_{w-v e q}\right)$ and in the surroundings $\left(C_{v s}\right)$ causes a water evaporation flux $\left(\varphi_{\text {evap }}\right)$ from the surface to the cold environment (Equation 6). 


$$
\text { if } \mathrm{T}>\text { Tif: }-\mathrm{D}_{\mathrm{w}} \frac{\partial \mathrm{C}_{\mathrm{w}}}{\partial \mathrm{x}}=\varphi_{\text {evap }}=\mathrm{h}_{\mathrm{m}}\left(\mathrm{C}_{\mathrm{w}-\mathrm{veq}}-\mathrm{C}_{\mathrm{vs}}\right)
$$

where $h_{m}$ is the external mass transfer coefficient and $T_{i f}$ is the initial freezing temperature.

During the second period, when surface starts freezing, ice sublimates from the sublimation front creating a dehydrated layer of thickness $e$. The water vapor flux $\left(\varphi_{v a p}\right)$ resulting from the ice sublimation front diffuses throughout the gas contained in the pores of the dehydrated layer until the product surface and then, throughout the external boundary layer. The steady-state water vapor diffusion in the dehydrated layer is assumed: the variation of the water vapor mass in the dehydrated layer is neglected. $\varphi_{v a p}$ is calculated using Equation 7 which involves the sum of the mass transfer resistances.

$$
\text { if } T<T_{\text {if }}: \quad C_{d m}\left(Y_{w}-Y_{b w}+Y_{i}\right) \frac{d e}{d t}=\varphi_{v a p}=\frac{C_{i-v e q}-C_{v s}}{\frac{e \tau}{\varepsilon D_{v}}+\frac{1}{h_{m}}}
$$

where $Y_{b w}$ is the fraction of bound water (dry basis), $C_{i-v e q}$ is the water vapor concentration in equilibrium with ice at the product surface, $\tau$ is the tortuosity of the dehydrated layer and $\varepsilon$ the porosity. $D_{v}$ is the water vapor diffusivity coefficient in the gas contained in the pores. It is assumed that partially frozen zone contains bound water, free water $\left(Y_{w^{-}} Y_{b w}\right)$ and ice whereas the dehydrated layer contains only bound water.

At the product surface, during the pre-cooling stage, a part of the heat conducted through the product is released by a convective transfer to the surroundings; the other part is consumed by water evaporation. During the second freezing stage, the heat is conducted in the product from the thermal center to the sublimation front. At the sublimation front, a part of the heat is used by ice sublimation and unfrozen water evaporation; the other part is conducted through the dehydrated layer and then, it is released by convection to the surroundings. Equation 8 is used as boundary condition for the heat flux $\left(\varphi_{h-s}\right)$, at the product surface for the pre-cooling stage $(e=0$ and $d e / d t=0)$ and at the sublimation front for the subcooling stage $\left(\varphi_{\text {evap }}=0\right)$.

$$
-\mathrm{k} \frac{\partial \mathrm{T}}{\partial \mathrm{x}}=\varphi_{\mathrm{h}-\mathrm{s}}=\frac{\mathrm{T}-\mathrm{T}_{\mathrm{g}}}{\frac{\mathrm{e}}{\mathrm{k}_{\mathrm{dl}}}+\frac{1}{\mathrm{~h}}}+\mathrm{C}_{\mathrm{dm}}\left(\left(\mathrm{Y}_{\mathrm{w}}-\mathrm{Y}_{\mathrm{bw}}\right) \mathrm{L}_{\mathrm{v}}+\mathrm{Y}_{\mathrm{i}} \mathrm{L}_{\mathrm{s}}\right) \frac{\mathrm{de}}{\mathrm{dt}}+\varphi_{\mathrm{evap}} \mathrm{L}_{\mathrm{v}}
$$

where $h$ is the convective heat transfer coefficient, $T_{g}$ is the temperature of the surroundings. $\mathrm{L}_{\mathrm{v}}$ and $\mathrm{L}_{\mathrm{s}}$ are respectively the latent heat of water evaporation and of ice sublimation and $k_{d l}$ is the thermal conductivity of the dehydrated layer.

\subsubsection{Transfer parameters and Tylose properties}

\section{Parameters available in the literature}


236 To be able to solve equations introduced in part 1.2.2 and 1.2.3, several parameters need to be 237 estimated. Table 2 summarizes these parameters and the selected methods for their estimation (all 238 notations are described in the nomenclature).

239 The estimation of the thermal conductivity of the frozen product must be predicted accurately as the 240 thermal conductivity of ice is significantly different to the conductivity of other components. 241 Therefore, three various models were tested in simulations: model 1 is and intermediate model 242 presented by Gulati and Datta (2013), model 2 was proposed by Pham and Willix (1990) to predict the 243 thermal conductivity of Tylose gel according to the temperature and model 3 is a Maxwell model 244 suggested by Cogné et al. (2003). The last model takes into account the physical structure of food 245 assuming that a component (ice) is dispersed in another one which is continuous (cryo-concentrated 246 solution). A similar relation was proposed by (Carson, 2006).

247 The tortuosity value of the dehydrated layer was also varied from 1.0 (Campañone et al., 2001) to 2.0 248 in simulations. The tortuosity qualifies the complexity of the pore network and has an impact on the 249 water vapor diffusivity throughout the dehydrated layer.

\section{Water activity, initial freezing temperature and ice content correlation}

251 Three other parameters used for the solving of heat and water transfer during freezing need to be 252 determined: $C_{w-v e q}\left(\right.$ or $\left.C_{i-v e q}\right), Y_{b w}$, and $Y_{i}$.

$253 C_{w-v e q}$, which represents the water vapor concentration in equilibrium with liquid water at the product 254 surface or sublimation location is calculated from Equation 9.

$$
\mathrm{C}_{\mathrm{w}-\mathrm{veq}}=\mathrm{a}_{\mathrm{w}} \mathrm{C}_{\mathrm{vsat}}
$$

$255 C_{v s a t}$ is the saturation vapor concentration in equilibrium with pure liquid water, which depends on the 256 product surface temperature. When the temperature is below $0^{\circ} \mathrm{C}, C_{w-v e q}$ is still calculated using pure 257 liquid water as reference state. $C_{v s a t}$ is then the vapor concentration in equilibrium with super-cooled 258 pure liquid water as it is shown on Figure 3. The liquid phase of the product contains different solutes 259 which makes that $a_{w}<1$. When the product is partially frozen, the solute concentration in the liquid 260 phase, which is directly related to the remaining liquid water content $Y_{w}$, increases and $a_{w}$ decreases. 261 Therefore, the water activity is function of temperature and liquid water content and its variation is 262 specific to each product. Nevertheless, a same expression can be used with parameters specific to each 263 product. The expression of Iglesias and Chirife (1976) was chosen (Equation 10).

$$
\left\{\begin{array}{l}
\mathrm{a}_{\mathrm{w}}=\exp \left(\frac{-\exp (\mathrm{bT}+\mathrm{c})}{\left(100 \mathrm{Y}_{\mathrm{w}}\right)^{\mathrm{r}}}\right) \text { if } \mathrm{T}>0{ }^{\circ} \mathrm{C} \\
\mathrm{a}_{\mathrm{w}}=\exp \left(\frac{-\exp (\mathrm{c})}{\left(100 \mathrm{Y}_{\mathrm{w}}\right)^{\mathrm{r}}}\right) \text { if } \mathrm{T}<0^{\circ} \mathrm{C}
\end{array}\right.
$$

$b, c$ and $r$ are constants, specific to a given product. To determine these parameters, a methodology was developed in this work, from equilibrium equation of pure water phase diagram (Figure 3) and from experimental data of enthalpy variation as a function of temperature. This methodology was applied to 
the case of Tylose. Parameter $b$ was taken as $-11.10^{-3}{ }^{\circ} \mathrm{C}^{-1}$ according to data found in literature (Iglesias and Chirife, 1976).

The saturation vapor pressure in equilibrium with pure liquid water $\left(P_{\text {sat.w }(T)}\right)$ and ice $\left(P_{\text {sat.i(T) }}\right)$ are expressed as a function of temperature (Figure 3) thanks to Clausius-Clapeyron expressions using the triple point $T_{0}=0^{\circ} \mathrm{C}$ as reference (Equation 11 and Equation 12).

$$
\begin{gathered}
\mathrm{P}_{\text {sat.w(T) }}=\mathrm{P}_{\text {sat(T0) }} \exp \left(\frac{-\mathrm{L}_{\mathrm{v}} \mathrm{M}_{\mathrm{w}}}{\mathrm{R}}\left(\frac{1}{\mathrm{~T}+273.15}-\frac{1}{273.15}\right)\right) \\
\mathrm{P}_{\text {sat.i(T) }}=\mathrm{P}_{\text {sat(T0) }} \exp \left(\frac{-\mathrm{L}_{\mathrm{S}} \mathrm{M}_{\mathrm{w}}}{\mathrm{R}}\left(\frac{1}{\mathrm{~T}+273.15}-\frac{1}{273.15}\right)\right)
\end{gathered}
$$

272 In these equations, $R$ is the universal gas constant and $M_{w}$ is the water molar mass.

273 From Equation 12 and the ideal gas equation, $C_{v s a t}$ is calculated with Equation 13.

$$
\mathrm{C}_{\mathrm{vsat}}=\frac{\mathrm{M}_{\mathrm{w}} \mathrm{P}_{\text {sat.w }}}{\mathrm{R}(\mathrm{T}+273.15)}
$$

As pure liquid water is used as the reference for the calculation of water activity, the initial freezing point is defined as when water activity for the unfrozen food equals the ratio of ice and water saturation vapor pressure (Figure 3) which is expressed by Equation 14.

$$
\mathrm{a}_{\mathrm{w}\left(\mathrm{Y}_{\mathrm{w} 0}\right)}=\frac{\mathrm{P}_{\text {sat.i }\left(\mathrm{T}_{\text {if }}\right)}}{\mathrm{P}_{\text {sat.w }\left(\mathrm{T}_{\mathrm{if}}\right)}}
$$

$Y_{w 0}$ is the initial water content of the product on a dry basis.

Thanks to Equation 10, 11, 12 and 14 parameter $r$ can be expressed as a function of $c$ and $T_{i f} \quad\left(T_{i f}=-\right.$ $1.0^{\circ} \mathrm{C}$ for Tylose) with Equation 15 .

$$
\mathrm{r}=\frac{\ln \left(\frac{-273.15 \exp (\mathrm{c}) \mathrm{R}\left(\mathrm{T}_{\mathrm{if}}+273.15\right)}{\mathrm{L}_{\mathrm{f}} \mathrm{M}_{\mathrm{w}} \mathrm{T}_{\text {if }}}\right)}{\ln \left(100 \mathrm{Y}_{\mathrm{w} 0}\right)}
$$

280 Below the initial freezing point $\left(T<T_{i f}\right)$, the rate of ice crystallization being fast relative to the rate of heat transfer throughout the product thickness, the food is locally considered in equilibrium. Thus, in the partially frozen zone, the remaining liquid food solution is in equilibrium with ice. For a given temperature, activity of the water in the liquid phase is equal of the activity of the water in the ice phase (Fennema, 1981; Storey and Stainsby, 1970). Thus, water activity is defined as the ratio of ice and 
expressed by Equation 16 .

$$
\begin{gathered}
a_{w_{\left(Y_{w}\right)}}=\frac{P_{\text {sat.i }(T)}}{P_{\text {sat.w }(T)}} \\
\text { where } Y_{w}=Y_{w 0}-Y_{i}
\end{gathered}
$$

Equation 16 combined with Equation 10, 11 and 12 leads to the following equation (Equation 17) which allows estimating the ice fraction on a dry basis $Y_{i}$ in the product as a function of temperature.

$$
Y_{i}=Y_{w 0^{-}} \frac{1}{100}\left[\frac{L_{f} M_{w}}{\exp (c) R}\left(\frac{1}{T+273.15}-\frac{1}{273.15}\right)\right]^{-1 / r}
$$

Nevertheless, the bound water can not crystallize so that the maximal value of ice content corresponds to the initial free water content in the product (Equation 18).

$$
Y_{i} \leq Y_{w 0}-Y_{b w}
$$

At a given temperature, Tylose contains carbohydrates and ash (mass fractions $X_{c h}=23 \%$ and $X_{a}=0.6 \%$ , specific heat capacity $C p_{c h}$ and $C p_{a}$ ), free and bound liquid water (mass fraction $X_{w}=76.4 \%$, specific heat capacity $C p_{w}$ ) and ice (mass fraction $X_{i}$, specific heat capacity $C p_{i}$ ). The ice mass fraction is obtained from Equation 17. The specific heat capacity of Tylose at this temperature is then obtained as the weighted average of the heat capacity of the components (Equations 19).

$$
\mathrm{Cp}=\sum_{\mathrm{j}}\left(\mathrm{X}_{\mathrm{j}} \mathrm{Cp}_{\mathrm{j}}\right)
$$

From Tylose mass specific heat capacity, Tylose enthalpy is then calculated as a function of temperature (Equation 20). The reference temperature was chosen at $T_{r e f}=-40^{\circ} \mathrm{C}\left(H_{\text {cal }(-40)}=0\right)$.

$$
\mathrm{H}_{\mathrm{cal}(\mathrm{T})}=\int_{\mathrm{T}_{\mathrm{ref}}}^{\mathrm{T}} \mathrm{Cp}_{(\mathrm{T})} \mathrm{dT}-\mathrm{X}_{\mathrm{i}(\mathrm{T})} \mathrm{L}_{\mathrm{f}}
$$

where $X_{i}$ is the ice fraction in the product on a humid basis.

The calculated enthalpies $\left(H_{c a l}\right)$ were then compared with experimental ones $\left(H_{\exp }\right)$ (Cleland and Earle, 1984) calculating the residues with Equation 21.

$$
\text { residues }=\int_{\mathrm{T}=-40^{\circ} \mathrm{C}}^{\mathrm{T}=20^{\circ} \mathrm{C}}\left(\mathrm{H}_{\mathrm{cal}(\mathrm{T})}-\mathrm{H}_{\exp (\mathrm{T})}\right)^{2} \mathrm{dt}
$$

301 By minimizing the residues, following parameter values were obtained for Tylose: $c=4.0, Y_{b w}=0.61$ $302\left(X_{b w}=0.14\right), r=1.5$ and $b=-11.10^{-3}{ }^{\circ} C^{-1}$. Figure 4 shows the calculated enthalpies considering these 303 parameter values in comparison with the experimental enthalpy curve. 
304 Finally, for the numerical solving, the finite volume method was used for the spatial discretization. The 305 mesh was refined near the product surface and a predictor corrector method was used for time 306 integration. The problem was solved using the Matlab ${ }^{\circledR}$ software.

\subsubsection{Model without considering internal water transfer}

308

The complete model presented above was compared to a simplified one which does not consider internal water transfer. The same equation (Equation 3) was used for heat transfer by conduction inside the product. At the product surface, the heat transfer by convection and the refrigeration effect of water evaporation or ice sublimation (assuming pure water) was expressed with Equation 22.

$$
\begin{gathered}
-\mathrm{k} \frac{\partial \mathrm{T}}{\partial \mathrm{x}}=\mathrm{h}\left(\mathrm{T}-\mathrm{T}_{\mathrm{g}}\right)+\varphi_{\text {vap }} \mathrm{L}_{\mathrm{v}-\mathrm{s}} \\
\text { with } \varphi_{\text {vap }}=\mathrm{h}_{\mathrm{m}}\left(\mathrm{C}_{\mathrm{vsat}}-\mathrm{C}_{\mathrm{vs}}\right)
\end{gathered}
$$

Where $C_{v s a t}$ is the vapor concentration in equilibrium with pure water or ice and $L_{v-s}$ is the latent heat of evaporation $\left(T>T_{i f}\right)$ or sublimation $\left(T<T_{i f}\right)$.

\section{RESULTS AND DISCUSSION}

\subsection{Validation against experimental data}

Experiments done with Tylose samples provided data on total relative weight loss and core temperature kinetics during the freezing process for 6 freezing operating conditions.

Simulations were also done with the same Tylose sample characteristics and the same 6 freezing process conditions. For experiments as well as for simulations, process was stopped when product core temperature reaches $-18^{\circ} \mathrm{C}$. Thanks to Equation 1, the experimental convective heat transfer coefficient $\mathrm{h}$ corresponding to each operating condition was calculated $(\mathrm{L}=80 \mathrm{~mm})$. These values were used as input freezing process parameters for simulations.

\subsubsection{Sensitivity analysis of the numerical model}

\section{Effect of tortuosity, thermal conductivity model and water diffusion coefficient}

Table 3 presents, for the freezing condition $-30^{\circ} \mathrm{C} / 3.9 \mathrm{~m} \mathrm{~s}^{-1}$, the numerical results for the freezing time and the relative weight loss according to the tortuosity value of the dehydrated layer (from 1.0 to 2.0) and to the model used to estimate the thermal conductivity of the frozen product. As it is shown on Table 3, the thermal conductivity model for the frozen product has a relatively small impact on the total freezing time. Indeed, the Biot number for the frozen product is below 1 (around 0. 4 in this case) which means that the internal resistance of the Tylose plate is lower than the external resistance due to the small thickness of the plate. Moreover, model 1 estimates thermal conductivities only $8 \%$ higher on average between $-1.0^{\circ} \mathrm{C}$ and $-20^{\circ} \mathrm{C}$ than model 2 and 3 ; model 2 and 3 are very close $(1.3 \%$ variation). 
334 For tortuosity values, results indicate a large effect on the weight loss: increasing the tortuosity value 335 significantly decreases the relative weight loss because the pore network is more complex and slows 336 down the water vapor diffusivity throughout the dehydrated layer and so ice sublimation at the 337 sublimation front. Thus, when tortuosity rises, the vaporization flux at the sublimation front lowers. 338 Since water vaporization is endothermic, it speeds up the cooling and so, if the sublimation flux 339 decreases, the freezing time increases.

340 These tables allow selecting the reference value for the tortuosity and the reference model to estimate 341 the thermal conductivity. The grey cases on Table 3 correspond to the selected values: the reference 342 tortuosity is 1.75 and the conductivity reference model is the one propose by Pham and Willix (1990)

343 Figure 5 presents the numerical and experimental temperature variation at product surface and core 344 during freezing. Numerical curves were obtained using the reference tortuosity and the reference model 345 of thermal conductivity. Figure 5 reveals that for the core temperature, the model slightly 346 underestimates the pre-cooling stage whereas the crystallization and sub-cooling period are well 347 estimated. When introducing samples in the freezing cabinet, ventilation and nitrogen injection were 348 stopped during the first minute of freezing. This can explained the small offset between experiments 349 and simulations. For the surface temperature, temperature could not be measured exactly at the surface. 350 The thermocouple was located approximately between 1 and $2 \mathrm{~mm}$ from the surface. The experimental 351 temperature is close to the predicted one for a depth of $2 \mathrm{~mm}$.

352 For the freezing condition $-30^{\circ} \mathrm{C} / 3.9 \mathrm{~m} \mathrm{~s}^{-1}$, Figure 6 shows the experimental relative weight loss after 5 , $35310,15,30$ and 45 minutes of freezing and the numerical prediction ( $\tau .=1.75$ and reference model for the 354 thermal conductivity). The simulation is run until $45 \mathrm{~min}$ for this comparison. The numerical relative 355 weight loss kinetics during freezing slightly overestimates the experimental one: $+0.18 \%$ after 5 min, $+0.20 \%$ after $10 \mathrm{~min},+0.19 \%$ after $15 \mathrm{~min},+0.12 \%$ after $30 \mathrm{~min}$ and $+0.04 \%$ at the end of freezing. However, the same trend is obtained: the weight loss rate is high at the beginning (precooling stage) and gradually slows down during the freezing and the sub-cooling stage.

A sensitivity analysis according to the water diffusivity coefficient, multiplying it by 2 or dividing it by 2 with respect to the reference model given in Table 2, showed that it has a small impact on the total weight loss (when core temperature reaches $-18^{\circ} \mathrm{C}$ ). The largest impact is for the slowest freezing condition: $-30^{\circ} \mathrm{C} / 3.9 \mathrm{~m} \mathrm{~s}^{-1}$, where dividing it by 2 decreases the total weight loss by $1.9 \%$ and multiplying it by 2 increases it by $3.7 \%$. Indeed, for this freezing condition, the precooling stage is the longest, nevertheless, the predicted water activity at the product surface remains close to one during this period. Moreover, the predicted water content at the product surface decreases almost in the same way and is $67.8 \%$ at the end of the precooling using the reference diffusivity, $65.4 \%$ dividing the diffusivity by 2 and $68.3 \%$ multiplying it by 2 . The impact of the water activity coefficient is becoming even less noticeable for faster freezing rate as the product starts freezing almost instantaneously (no more water diffusion in the frozen product).

\section{Comparison with the simplified model (without considering internal water transfer)}

Table 4 compares results of total relative weight losses and freezing times obtained experimentally with 
those predicted using the developed complete model (reference values for tortuosity and thermal conductivity model) and those predicted with the simplified model which does not consider internal water transfer (presented in Section 1.2.5). For weight losses, results are very different. The weight loss is overestimated by the simplified model for slow freezing $\left(-30^{\circ} \mathrm{C}\right.$ and $\left.-50^{\circ} \mathrm{C}\right)$ in comparison with the experimental data and results predicted by the complete model. In this case, the resistance of water vapor transfer through the dehydrated layer cannot be neglected. For freezing at $-100^{\circ} \mathrm{C}$, the weight loss is still overestimated by the simplified model in comparison with the complete one, but, it is closer to experimental data. In this case, the resistance of the dehydrated layer (thickness or tortuosity) may be overestimated by the complete 381 model.

382 For freezing times, the simplified model gives slightly lower values than the complete model at $-30^{\circ} \mathrm{C}$ because it overestimates the cooling effect of vaporization. For low freezing temperatures $\left(-50^{\circ} \mathrm{C}\right.$ and $100^{\circ} \mathrm{C}$ ), the values obtained with the simplified model are close to the prediction of the complete model because the dehydrated layer is finer. In conclusion, a model including internal water transfer, notably the resistance of water vapor transfer through the dehydrated surface layer, is necessary to accurately predict the weight loss but does not improve significantly the prediction of freezing time.

\subsubsection{Total relative weight loss and freezing time: experimental and numerical results}

Figure 7 compares the experimental data of total relative weight losses (when core temperature reaches $-18^{\circ} \mathrm{C}$ ) and the numerical ones $(\tau=1.75$ and reference model of thermal conductivity for the frozen product) according to the three freezing temperatures $\left(-30^{\circ} \mathrm{C},-50^{\circ} \mathrm{C}\right.$ and $\left.-100^{\circ} \mathrm{C}\right)$ and the two gas flow velocities $\left(3.9 \mathrm{~m} \mathrm{~s}^{-1}\right.$ and $\left.7.7 \mathrm{~m} \mathrm{~s}^{-1}\right)$. The average absolute deviation between the numerical predictions and experimental values is 0.07 . The difference is very low for the freezing conditions of $-30^{\circ} \mathrm{C}$ and $50^{\circ} \mathrm{C}$. Nevertheless, the gap is a little larger at $-100^{\circ} \mathrm{C}$. The models tends to underestimate the total weight loss. This can be explained both by the lack of accuracy of the experimental data for total relative weight losses and of model parameters at this low freezing temperature. Regarding the experimental measurements, the time during which ventilation and nitrogen injection are switched off (about $1 \mathrm{~min}$ ), when samples are introduced and initial weighing is done, is relatively long compared to the freezing time at this temperature (14 min for $3.9 \mathrm{~m} \mathrm{~s}^{-1}$ and $10 \mathrm{~min}$ for $7.7 \mathrm{~m} \mathrm{~s}^{-1}$ ). This may introduce some measurement artifacts and explain the larger difference between experimental and numerical results at $-100^{\circ} \mathrm{C}$.

Figure 8 presents the experimental freezing times for the product core temperature to reach $-18^{\circ} \mathrm{C}$ in comparison with numerical ones ( $\tau=1.75$ and reference model of thermal conductivity for the frozen product) according to the three freezing temperatures $\left(-30^{\circ} \mathrm{C},-50^{\circ} \mathrm{C}\right.$ and $\left.-100^{\circ} \mathrm{C}\right)$ and the two gas flow velocities $\left(3.9 \mathrm{~m} \mathrm{~s}^{-1}\right.$ and $\left.7.7 \mathrm{~m} \mathrm{~s}^{-1}\right)$. It appears that the experimental freezing time is always longer than the numerical one. This can be explained by the fact that, experimentally, the first minute of freezing is done without ventilation and nitrogen injection. Moreover, the super-cooling is not taken into account in the model, it is assumed that the system is always at equilibrium. In addition, product expansion due to freezing which is about $5 \%$ is not included to the model, this can also explain an underestimation of 
the freezing time. Indeed, the thermal resistance of the frozen product is therefore underestimated.

412 For the validation of the dehydrated layer thickness, some measurements were done on frozen sample 413 images obtained by X-ray micro-tomography. Nevertheless, resolution of X-ray micro-tomography was not sufficient to analyze and accurately distinguish pores forming the dehydrated layer.

\subsection{Influence of operating freezing conditions on predicted temperature and dehydration evolutions}

Simulations were run $(\tau=1.75$ and reference model of thermal conductivity for the frozen product) until the product core temperature reach $-18^{\circ} \mathrm{C}$ for the 6 studied operating conditions. Figure 9 shows the influence of freezing temperature and flow velocity on product core temperature, surface temperature, relative weight loss and dehydrated layer thickness variation over freezing time. On Figure 9a, a plateau can be observed for the core temperature when it reaches $T_{i f}\left(-1.0^{\circ} \mathrm{C}\right)$.

Both freezing temperature and flow velocity have a great influence on the product freezing kinetics and on the progress of the dehydration front. Decreasing the gas temperature or increasing the flow velocity (higher $h$ ) accelerates the heat transfer kinetics and thus the product freezing kinetics. It takes less time for the thermal center to reach $-18^{\circ} \mathrm{C}$ and therefore time for water evaporation and ice sublimation is shorter. Moreover, for a lower gas temperature and a higher flow velocity, the product surface temperature decreases faster (Figure 9b): therefore, the water vapor concentration at the surface also decreases reducing the vapor flux from the product surface. Both phenomena mentioned previously lead to lower weight losses and thinner dehydrated layers (Figure 9c and 9d). The less efficient freezing condition: $-30^{\circ} \mathrm{C} / 3.9 \mathrm{~m} \mathrm{~s}^{-1}$ corresponds to a standard mechanical freezing process, it leads to a relative weight loss of $1.62 \%$ and a dehydrated layer thickness of $0.318 \mathrm{~mm}$. The freezing condition $-50^{\circ} \mathrm{C} / 7.7$ $\mathrm{m} \mathrm{s}^{-1}$ corresponds to an efficient mechanical freezing process, it halves the relative weight loss $(0.87 \%)$ and the dehydrated layer thickness is $0.130 \mathrm{~mm}$. The most efficient freezing condition is $-100^{\circ} \mathrm{C} / 7.7 \mathrm{~m}$ $\mathrm{s}^{-1}$ which is a cryogenic freezing process, the relative weight loss is $0.28 \%$, it represents a third of the weight loss get for the efficient mechanical process and 5.8 times less than the less efficient mechanical process. The dehydrated layer thickness is only $0.039 \mathrm{~mm}$.

Figure 10 presents the total relative weight loss (when the product core temperature is at $-18^{\circ} \mathrm{C}$ ) due to water evaporation and due to ice sublimation (and unfrozen water evaporation) according to the 6 freezing operating conditions. Figure 10 shows that the relative weight loss due to water evaporation ( $W L_{\text {evap }}$ ) during the first freezing stage is very low and negligible for freezing conditions $-50^{\circ} \mathrm{C} / 7.7 \mathrm{~m} \mathrm{~s}^{-}$ ${ }^{1}\left(W L_{\text {evap }}=0.07 \%\right) ;-100^{\circ} \mathrm{C} / 3.9\left(W L_{\text {evap }}=0.05 \%\right)$ and $-100^{\circ} \mathrm{C} / 7.7 \mathrm{~m} \mathrm{~s}^{-1}\left(W L_{\text {evap }}=0.03 \%\right)$ because as it is shown on Figure $9 \mathrm{~b}$, product surface freezes almost instantly being in contact with the very cold and highly ventilated environment.

\section{CONCLUSIONS}

A numerical model for predicting freezing time, weight loss during freezing and thickness of a dehydrated layer at the product surface for unwrapped non-porous food products was developed. A methodology was established to accurately determine and link expressions to calculate water activity, 
448 initial freezing temperature and ice fraction formed in the product. These correlations were set thanks

449 to Clausius-Clapeyron phase equilibrium equations and thanks to experimental data related to the 450 variation of the product enthalpy as a function of temperature.

451 Numerical results of relative weight loss were compared to experimental ones obtained with Tylose 452 samples for 6 operating conditions in the mechanical and cryogenic freezing field. Results showed a 453 good agreement between numerical and experimental data.

454 This numerical model allows studying the influence of the freezing operating conditions: freezing 455 temperature and gas flow velocity on the product freezing kinetics, the relative weight loss and the 456 thickness of the dehydrated layer due to ice sublimation at its surface.

457 This predictive tool is reliable and can be applied for various food materials both for mechanical and 458 cryogenic freezing conditions.

\section{NOMENCLATURE}
$\mathrm{a}_{\mathrm{w}} \quad$ Water activity
$\mathrm{b}, \mathrm{c}, \mathrm{r}$ Parameters for water activity expression
$\mathrm{C}_{\mathrm{dm}} \quad$ Dry matter concentration in the product
( $\mathrm{kg}$ of dry matter $\mathrm{m}^{-3}$ of product)
$\mathrm{Cp} \quad$ Product mass specific heat capacity $\left(\mathrm{J} \mathrm{kg}^{-1}{ }^{\circ} \mathrm{C}^{-1}\right)$ $\left(\mathrm{J} \mathrm{kg}^{-1}{ }^{\circ} \mathrm{C}^{-1}\right)$
$\mathrm{C}_{\mathrm{i}-\mathrm{veq}}$ Water vapor concentration in equilibrium with ice at the product surface $\left(\mathrm{kg} \mathrm{m}^{-3}\right)$
$\mathrm{Cp}_{\text {app }}$ Product apparent mass specific heat capacity
$\mathrm{Cp}_{\mathrm{g}} \quad$ Gas mass specific heat capacity
$\mathrm{Cp}_{\mathrm{j}} \quad$ Mass specific heat capacity of the $\left(\mathrm{J} \mathrm{kg}^{-1}{ }^{\circ} \mathrm{C}^{-1}\right)$
$\mathrm{C}_{\mathrm{vs}}$ Water vapor concentration in the surrounding $\mathrm{C}_{\mathrm{vsat}}$ component $\mathrm{j}\left(\mathrm{J} \mathrm{kg}^{-1}{ }^{\circ} \mathrm{C}^{-1}\right)$ gas $\left(\mathrm{kg} \mathrm{m}^{-3}\right)$
$\mathrm{C}_{\mathrm{vsat}} \quad$ Saturation water vapor concentration
$\mathrm{C}_{\mathrm{w}} \quad$ Liquid water mass concentration $\left(\mathrm{kg} \mathrm{m}^{-3}\right)$
$\mathrm{C}_{\mathrm{w}-\mathrm{veq}}$
$\left(\mathrm{kg} \mathrm{m}^{-3}\right)$

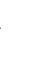


$\mathrm{k}_{\mathrm{j}} \quad$ Thermal conductivity of the component $\mathrm{j} \quad \mathrm{k}_{\mathrm{pa}}$ $\left(\mathrm{W} \mathrm{m} \mathrm{m}^{-1} \mathrm{C}^{-1}\right)$

L Length of the sample (plate) (m)

$\mathrm{L}_{\mathrm{v}-\mathrm{s}} \quad$ Latent heat of evaporation or sublimation $\left(\mathrm{J} \mathrm{kg}^{-1}\right)$

$\mathrm{L}_{\mathrm{v}} \quad$ Latent heat of water evaporation $\left(\mathrm{J} \mathrm{kg}^{-1}\right)$

$\mathrm{Nu} \quad$ Nusselt number

$\mathrm{P}_{\text {sat.i }} \quad$ Saturation pressure of water vapor in equilibrium with ice $(\mathrm{Pa})$

R Universal gas constant $\left(8.314 \mathrm{~J} \mathrm{~K}^{-1} \mathrm{~mol}^{-1}\right)$

Sc Schmidt number

$\mathrm{T} \quad$ Product temperature $\left({ }^{\circ} \mathrm{C}\right)$

$\mathrm{T}_{\text {if }} \quad$ Initial freezing temperature $\left({ }^{\circ} \mathrm{C}\right)$

$\mathrm{T}_{\text {ref }} \quad$ Reference temperature $\left({ }^{\circ} \mathrm{C}\right)$

$v_{j} \quad$ Volumetric fraction of the component $j$

$\mathrm{v}_{\mathrm{s}} \quad$ Flow velocity in the surrounding gas $\left(\mathrm{m} \mathrm{s}^{-1}\right)$

$\mathrm{x} \quad$ Location in the product (m)

$\mathrm{X}_{\mathrm{j}} \quad$ Mass fraction of the component $\mathrm{j}$

$\mathrm{Y}_{\mathrm{i}} \quad$ Ice content ( $\mathrm{kg}$ of ice $\mathrm{kg}^{-1}$ of dry matter)

$\mathrm{Y}_{\mathrm{bw}} \quad$ Bound water content in dry basis ( $\mathrm{kg}$ of water $\mathrm{kg}^{-1}$ of dry matter)

$\alpha \quad$ Geometric factor ( $\alpha=0$ for an infinite plate, $\alpha=1$ for a cylinder and $\alpha=2$ in case of a sphere)

$\mu_{\mathrm{g}} \quad$ Gas dynamic viscosity (Pa s)

$\varphi_{\mathrm{h}-\mathrm{s}} \quad$ Heat flow at product surface $\left(\mathrm{W} \mathrm{m}^{-2}\right)$ $\mathrm{k}_{\mathrm{pa}} \quad$ Thermal conductivity of the cryoconcentrated solution calculated with a parallel model $\left(\mathrm{W} \mathrm{m}^{-1}{ }^{\circ} \mathrm{C}^{-1}\right)$

$\mathrm{L}_{\mathrm{f}} \quad$ Latent heat of fusion $\left(\mathrm{J} \mathrm{kg}^{-1}\right)$

Ls Latent heat of ice sublimation $\left(\mathrm{J} \mathrm{kg}^{-1}\right)$

$\mathrm{M}_{\mathrm{w}} \quad$ Water molar mass $\left(\mathrm{kg} \mathrm{mol}^{-1}\right)$

Pr Prandtl number

$\mathrm{P}_{\text {sat.w }} \quad$ Saturation pressure of water vapor in equilibrium with liquid water $(\mathrm{Pa})$

Re Reynolds number

t Time (s)

$\mathrm{T}_{\mathrm{g}} \quad$ Temperature of the surrounding gas $\left({ }^{\circ} \mathrm{C}\right)$

$\mathrm{T}_{\mathrm{m}} \quad$ Mean temperature between the product surface and the

$\mathrm{T}_{\mathrm{s}} \quad$ Temperature of the product surface $\left({ }^{\circ} \mathrm{C}\right)$

$V_{\text {pore }} \quad$ Volume of pores $\left(\mathrm{m}^{3}\right)$

$\mathrm{V}_{\text {tot }} \quad$ Total volume $\left(\mathrm{m}^{3}\right)$

$\mathrm{X}_{\mathrm{i}} \quad$ Mass fraction of ice

$\mathrm{X}_{\mathrm{bw}} \quad$ Mass fraction of bound water

$\mathrm{Y}_{\mathrm{w}} \quad$ Liquid water content

( $\mathrm{kg}$ of water $\mathrm{kg}^{-1}$ of dry matter)

$\mathrm{Y}_{\mathrm{w} 0} \quad$ Initial water content of the product in dry basis

( $\mathrm{kg}$ of water $\mathrm{kg}^{-1}$ of dry matter)

$\varepsilon_{\mathrm{dl}} \quad$ Porosity of the dehydrated layer

$\varphi_{\text {evap }} \quad$ Water evaporation flux $\left(\mathrm{kg} \mathrm{m}^{-2} \mathrm{~s}^{-1}\right)$

$\varphi_{\text {vap }} \quad$ Vaporization (ice sublimation and unfrozen water evaporation) flux 

$\left(\mathrm{kg} \mathrm{m}^{-2} \mathrm{~s}^{-1}\right)$
$\rho \quad$ Product density $\left(\mathrm{kg} \mathrm{m}^{-3}\right)$
$\rho_{\mathrm{g}} \quad$ Gas Density $\left(\mathrm{kg} \mathrm{m}^{-3}\right)$
$\rho_{\mathrm{j}} \quad$ Density of the component $\mathrm{j}\left(\mathrm{kg} \mathrm{m}^{-3}\right)$
$\tau \quad$ Tortuosity of the dehydrated layer

\section{ACKNOWLEDGEMENTS}

The authors gratefully acknowledge the financial support granted by the CIFRE department (Conventions Industrielles de Formation par la Recherche) from the French ANRT (Association Nationale Recherche et Technologie).

\section{REFERENCES}

Anderson, B.A., Singh, R.P., (2005). Moisture diffusivity in Tylose gel (Karlsruhe test material). Journal of Food Science 70(5), 331-337.

Andreasen, M.B. (2009). Modelling of Heat and Mass Transfer in Food Products In Proceedings of the Comsol Conference, Milan.

Boonsumrej, S., Chaiwanichsiri, S., Tantratian, S., Suzuki, T., Takai, R., (2007). Effects of freezing and thawing on the quality changes of tiger shrimp (Penaeus monodon) frozen by air-blast and cryogenic freezing. Journal of Food Engineering 80(1), 292-299.

Bustabad, O.M., (1999). Weight loss during freezing and the storage of frozen meat. Journal of Food Engineering 41(1), 1-11.

Campanone, L.A., Roche, L.A., Salvadori, V.O., Mascheroni, R.H., (2002). Monitoring of weight losses in meat products during freezing and frozen storage. Food Science and Technology International 8(4), 229-238.

Campañone, L.A., Salvadori, V.O., Mascheroni, R.H., (2001). Weight loss during freezing and storage of unpackaged foods. Journal of Food Engineering 47(2), 69-79.

Campañone, L.A., Salvadori, V.O., Mascheroni, R.H., (2005a). Food freezing with simultaneous surface dehydration: approximate prediction of freezing time. International Journal of Heat and Mass Transfer 48(6), 1205-1213.

Campañone, L.A., Salvadori, Y.O., Mascheroni, R.H., (1998). Finite-difference method to solve coupled heat and mass balances with simultaneous surface dehydration during freezing. Latin American Applied Research 28, 83-88.

Carson, J.K., (2006). Review of effective thermal conductivity models for foods. International Journal of Refrigeration 29(6), 958-967.

Cleland, A.C., Earle, R.L., (1984). Assessment of Freezing Time Prediction Methods. Journal of Food Science 49(4), 1034-1042.

Cogné, C., Andrieu, J., Laurent, P., Besson, A., Nocquet, J., (2003). Experimental data and modelling of thermal properties of ice creams. Journal of Food Engineering 58(4), 331-341.

Espinoza Rodezno, L.A., Sundararajan, S., Solval, K.M., Chotiko, A., Li, J., Zhang, J., Alfaro, L., Bankston, J.D., Sathivel, S., (2013). Cryogenic and air blast freezing techniques and their effect on the quality of catfish fillets. LWT - Food Science and Technology 54(2), 377-382. 
493 Fennema, O., (1981). Water activity at subfreezing temperatures, in: Stewart, G.F. (Ed.), Water Activity: 494 Influences on Food Quality. Academic Press, pp. 713-732.

495 Gulati, T., Datta, A.K., (2013). Enabling computer-aided food process engineering: Property estimation 496 equations for transport phenomena-based models. Journal of Food Engineering 116(2), 483-504.

497 Hamdami, N., Monteau, J.-Y., Le Bail, A., (2004a). Heat and mass transfer in par-baked bread during freezing. 498 Food Research International 37(5), 477-488.

499 Hamdami, N., Monteau, J.-Y., Le Bail, A., (2004b). Simulation of coupled heat and mass transfer during 500 freezing of a porous humid matrix. International Journal of Refrigeration 27(6), 595-603.

501 Iglesias, H.A., Chirife, J., (1976). Prediction of the effect of temperature on water sorption isotherms of food 502 material. International Journal of Food Science \& Technology 11(2), 109-116.

503 Lambrinos, G., Aguirre-Puente, J., (2003). The weight loss of frozen meat. Experimentation and prediction by 504 using tylose. International Journal of Refrigeration 26(2), 256-259.

505 Mulot, V., Benkhelifa, H., Pathier, D., Ndoye, F.T., Flick, D., (2018). Measurement of food dehydration during 506 freezing: Development of an experimental tool and application to tylose, In Proceedings of the 5th IIR 507 International Conference on Sustainability and the Cold Chain, Beijing.

508 Pham, Q.T., (2006). Modelling heat and mass transfer in frozen foods: a review. International Journal of 509 Refrigeration 29(6), 876-888.

510 Pham, Q.T., (2014). Freezing time formulas for foods with low moisture content, low freezing point and for 511 cryogenic freezing. Journal of Food Engineering 127, 85-92.

512 Pham, Q.T., Willix, J., (1984). Model for food desiccation in frozen storage. Journal of Food Science 49, 12755131281.

514 Pham, Q.T., Willix, J., (1990). Effect of biot-number and freezing rate on accuracy of some food freezing time 515 prediction methods. Journal of Food Science 55(5), 1429-1434.

516 Storey, R.M., Stainsby, G., (1970). The equilibrium water vapour pressure of frozen cod. International Journal of 517 Food Science \& Technology 5(2), 157-163.

518 Tocci, A.M., Mascheroni, R.H., (1995). Numerical-models for the simulation of the simultaneous heat and mass519 transfer during food freezing and storage. International Communications in Heat and Mass Transfer 22(2), 251520260 . 
Figure 1: Operating diagram of the freezing cabinet-Top view

Figure 2: Heat and water transfers during pre-cooling stage (a) and freezing stage (b) (1: unfrozen zone; 2: partially frozen zone; 3: Dehydrated layer) ..................................................................... 3

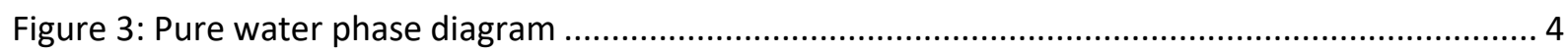

Figure 4: Calculated enthalpies and experimental enthalpy curve according to temperature .............. 5

Figure 5: Numerical and experimental surface and core temperatures variations during freezing

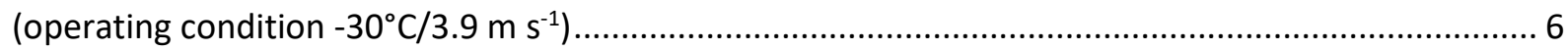

Figure 6: Experimental and numerical relative weight loss variations over freezing time for the

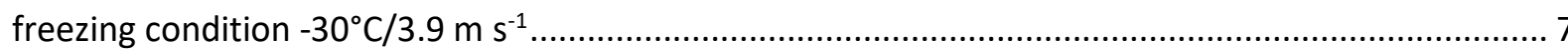

Figure 7: Experimental total relative weight losses against numerical ones according to freezing

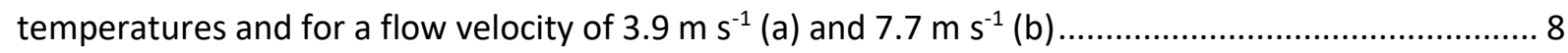

Figure 8: Experimental freezing times for the core temperature to reach $-18^{\circ} \mathrm{C}$ against numerical ones according to freezing temperatures and for a flow velocity of $3.9 \mathrm{~m} \mathrm{~s}^{-1}$ (a) and $7.7 \mathrm{~m} \mathrm{~s}^{-1}$ (b) .............. 9 Figure 9: Core temperature (a), surface temperature (b), relative weight loss (c) and dehydrated layer thickness (d) according to freezing time for the 6 freezing operating conditions 10

Figure 10: Predicted total relative weight loss (water evaporation + ice sublimation) according to freezing operating conditions for Tylose. 


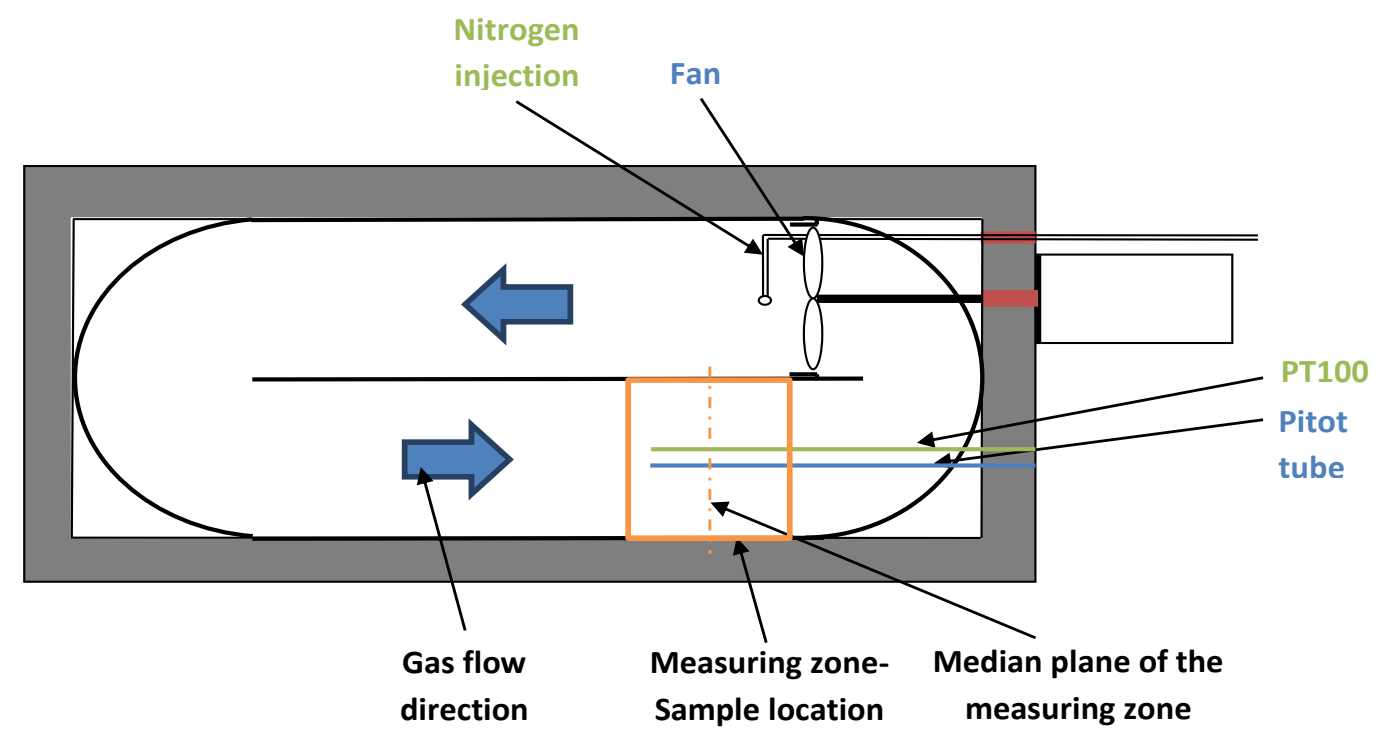

Figure 1: Operating diagram of the freezing cabinet-Top view 


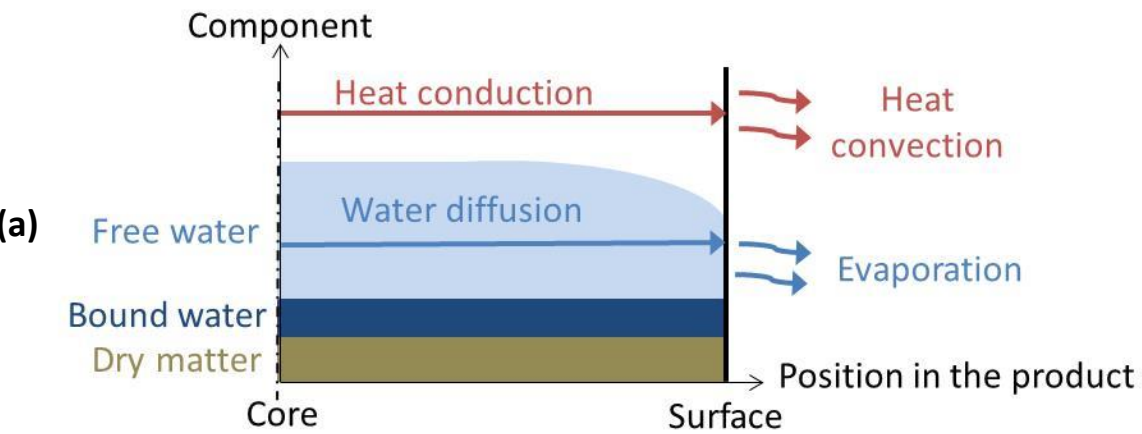

Symmetry axis or plan

(b)

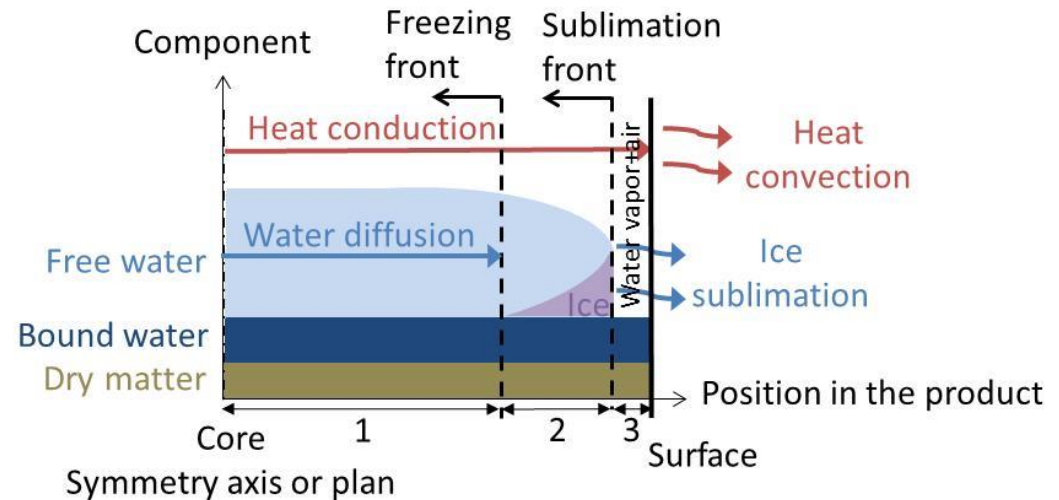

Figure 2: Heat and water transfers during pre-cooling stage (a) and freezing stage (b) (1: unfrozen zone; 2: partially frozen zone; 3: Dehydrated layer) 


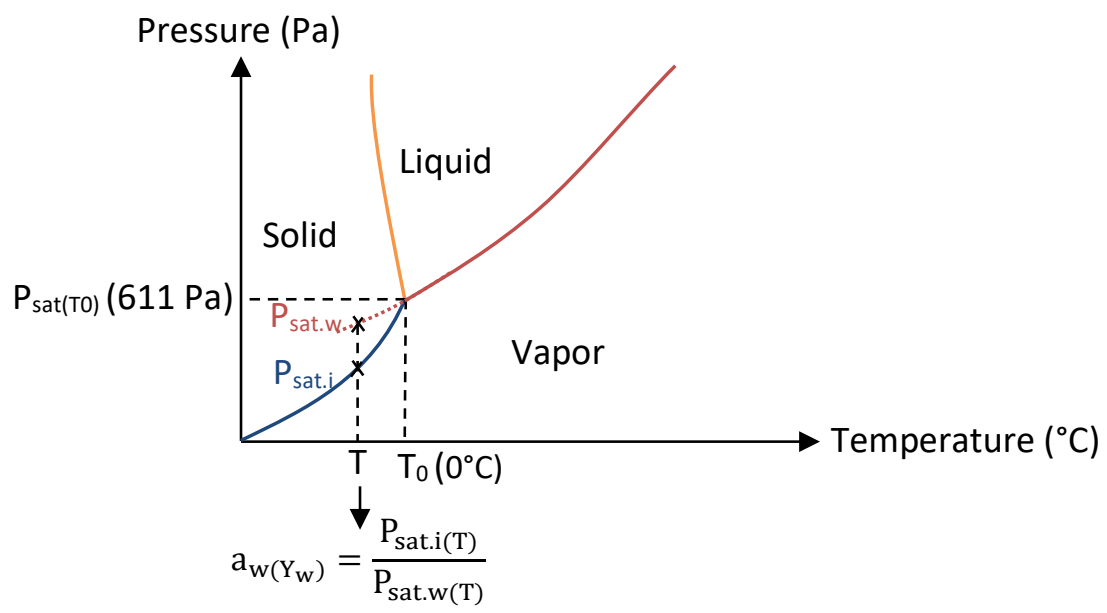

Figure 3: Pure water phase diagram 


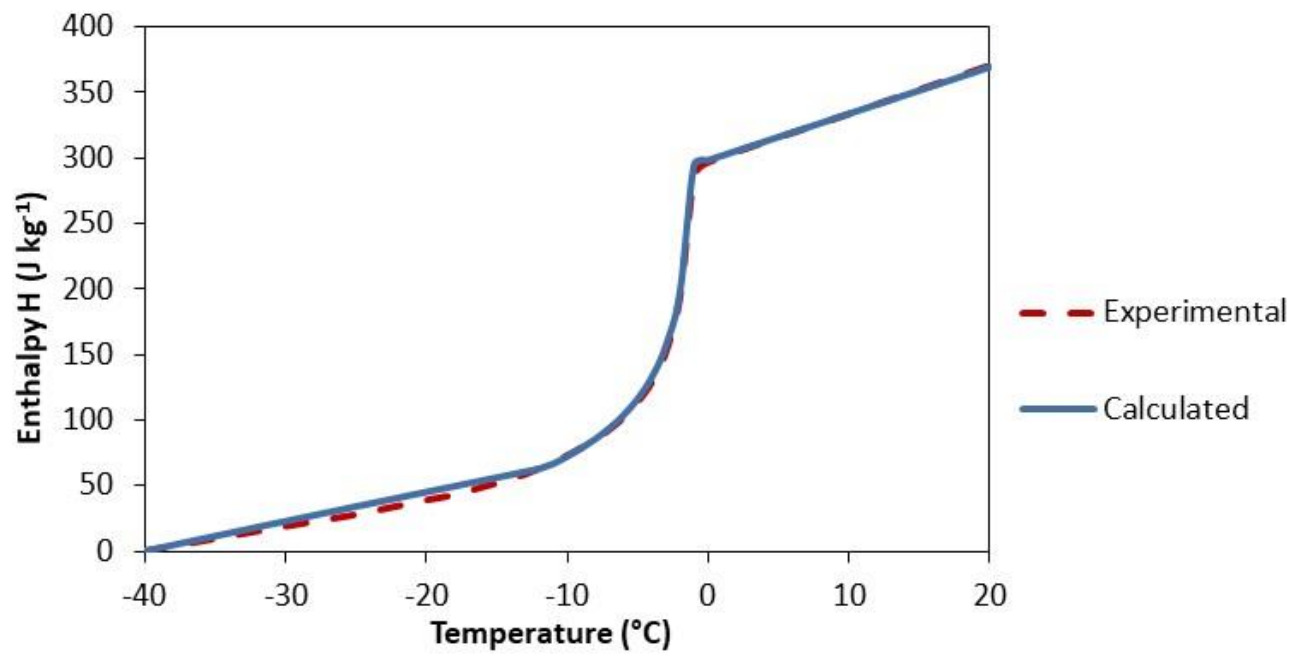

Figure 4: Calculated enthalpies and experimental enthalpy curve according to temperature 


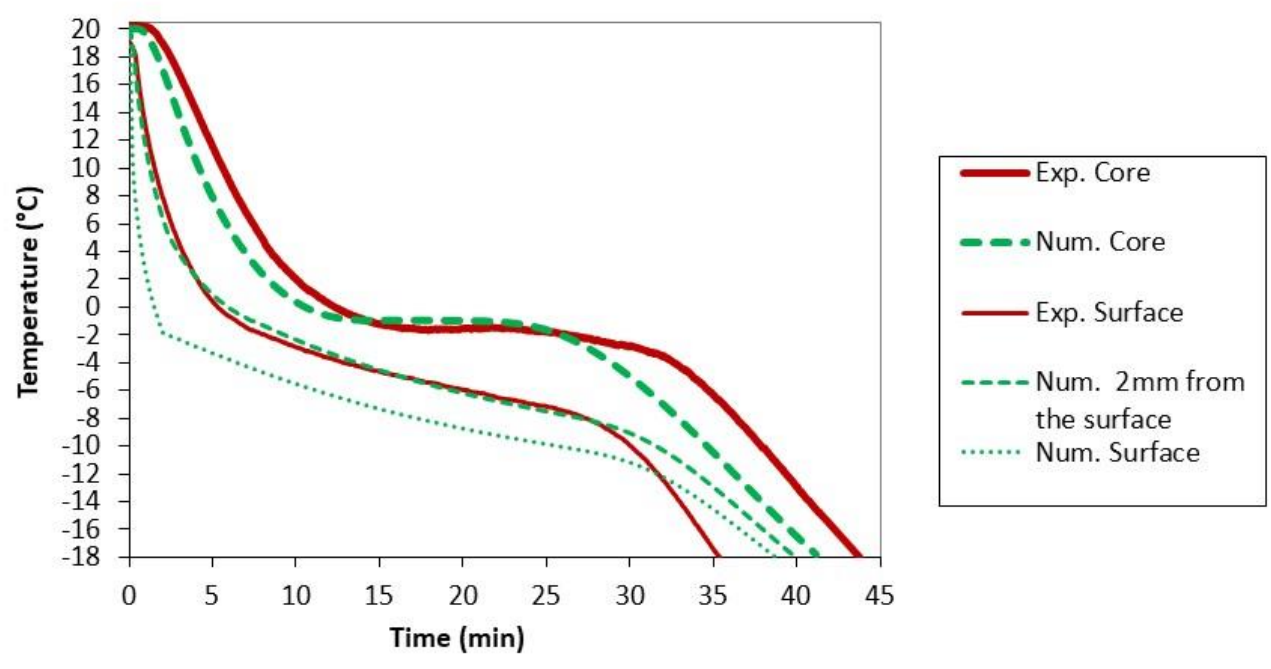

Figure 5: Numerical and experimental surface and core temperatures variations during freezing (operating condition $-30^{\circ} \mathrm{C} / 3.9 \mathrm{~m} \mathrm{~s}^{-1}$ ) 


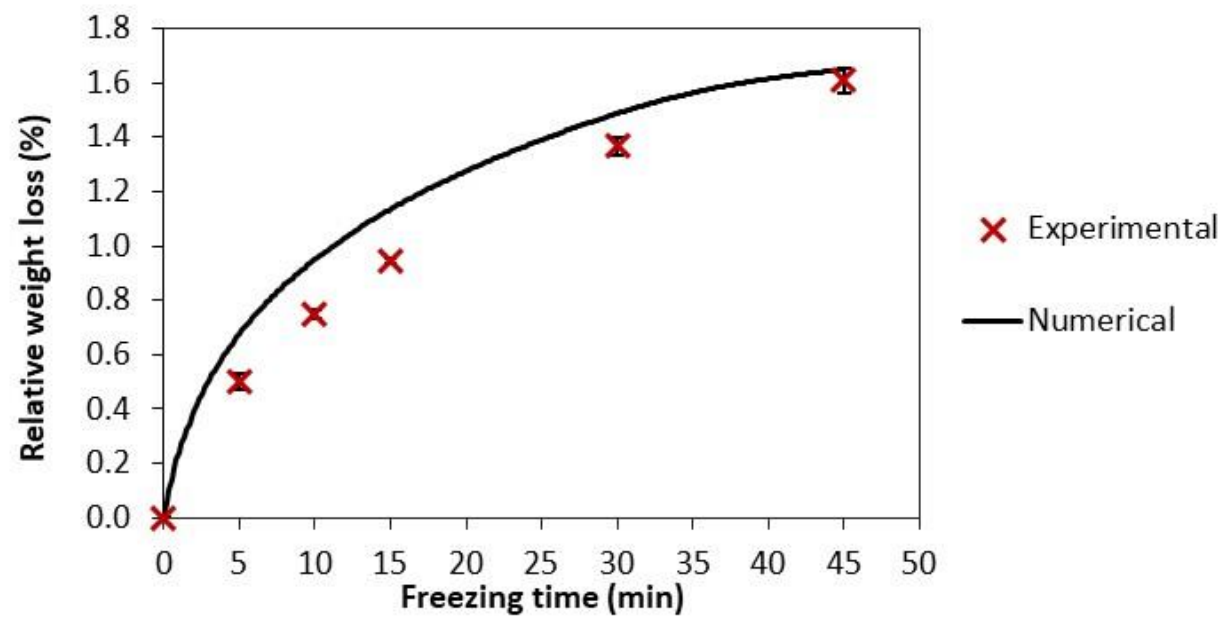

Figure 6: Experimental and numerical relative weight loss variations over freezing time for the freezing condition $-30^{\circ} \mathrm{C} / 3.9 \mathrm{~m} \mathrm{~s}^{-1}$ 


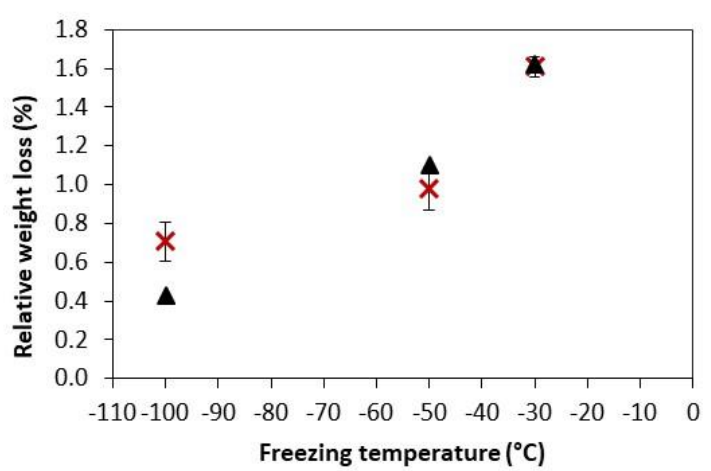

(a) $3.9 \mathrm{~m} \mathrm{~s}^{-1}$

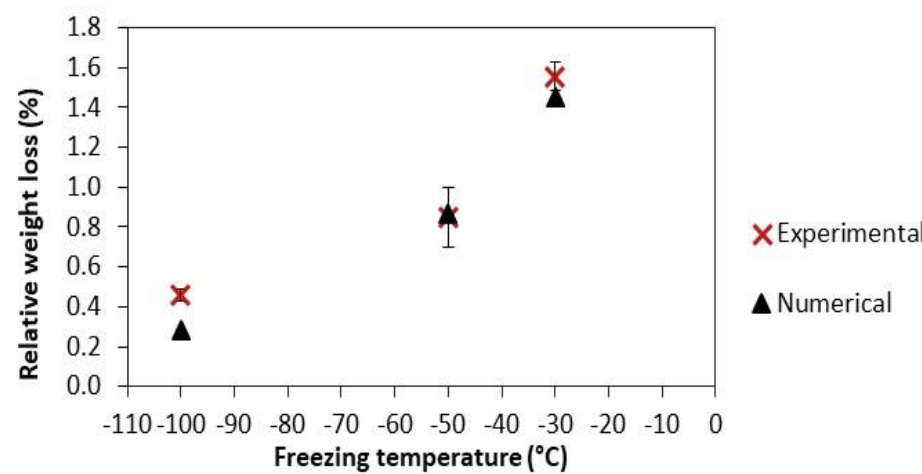

(b) $7.7 \mathrm{~m} \mathrm{~s}^{-1}$

Figure 7: Experimental total relative weight losses against numerical ones according to freezing temperatures and for a flow velocity of $3.9 \mathrm{~m} \mathrm{~s}^{-1}$ (a) and $7.7 \mathrm{~m} \mathrm{~s}^{-1}$ (b) 


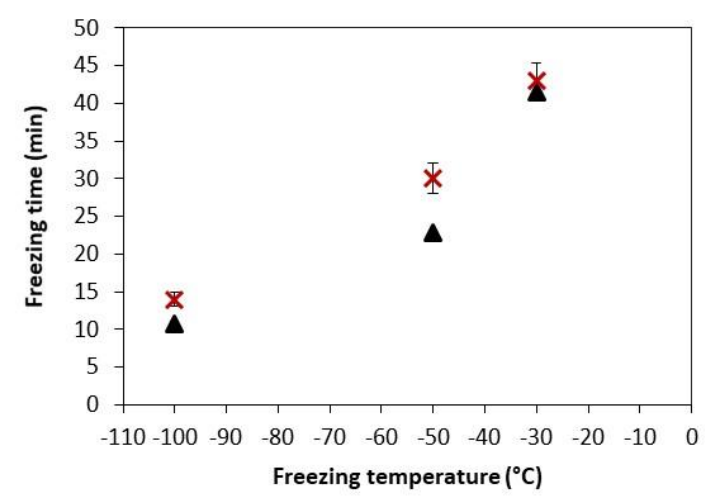

(a) $3.9 \mathrm{~m} \mathrm{~s}^{-1}$

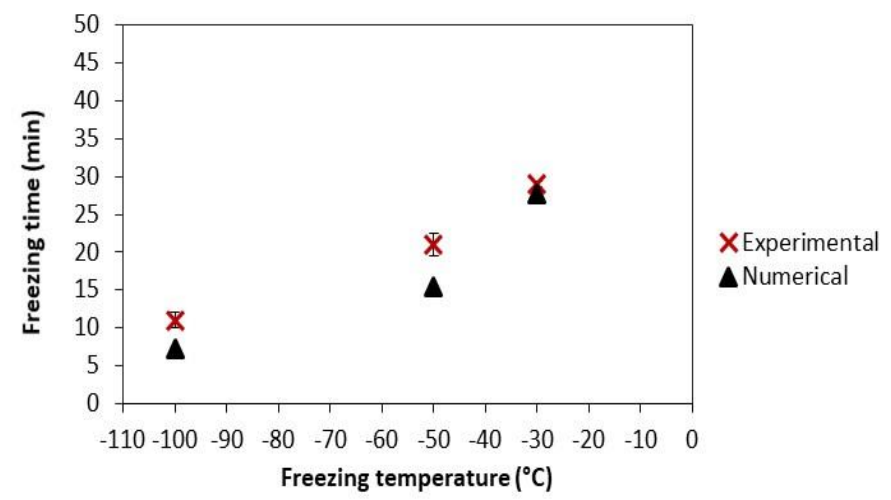

(b) $7.7 \mathrm{~m} \mathrm{~s}^{-1}$

Figure 8: Experimental freezing times for the core temperature to reach $-18^{\circ} \mathrm{C}$ against numerical ones according to freezing temperatures and for a flow velocity of $3.9 \mathrm{~m} \mathrm{~s}^{-1}$ (a) and $7.7 \mathrm{~m} \mathrm{~s}^{-1}$ (b) 


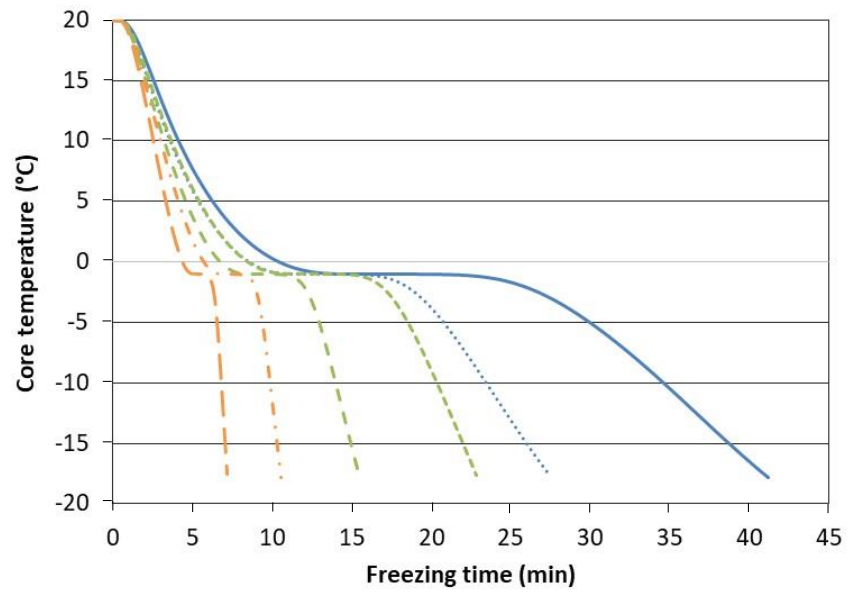

(a) Core temperature

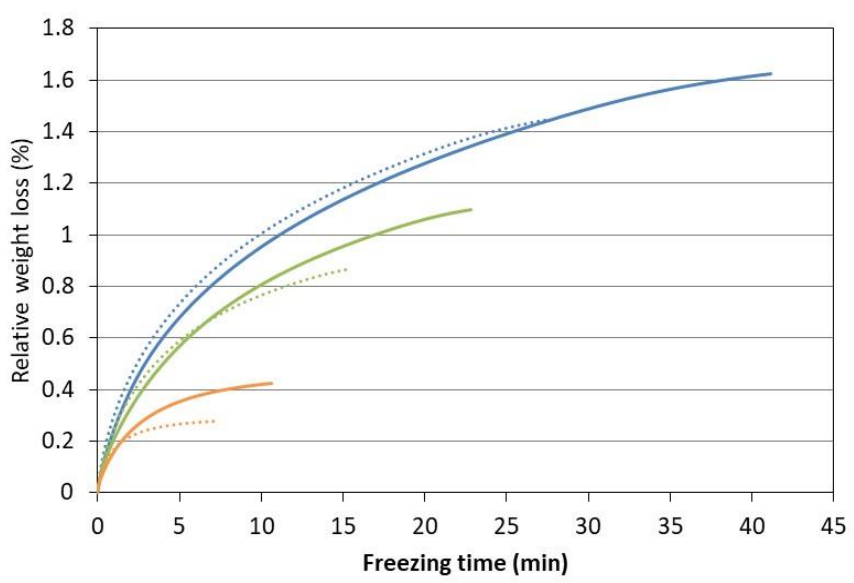

(c) Relative weight loss

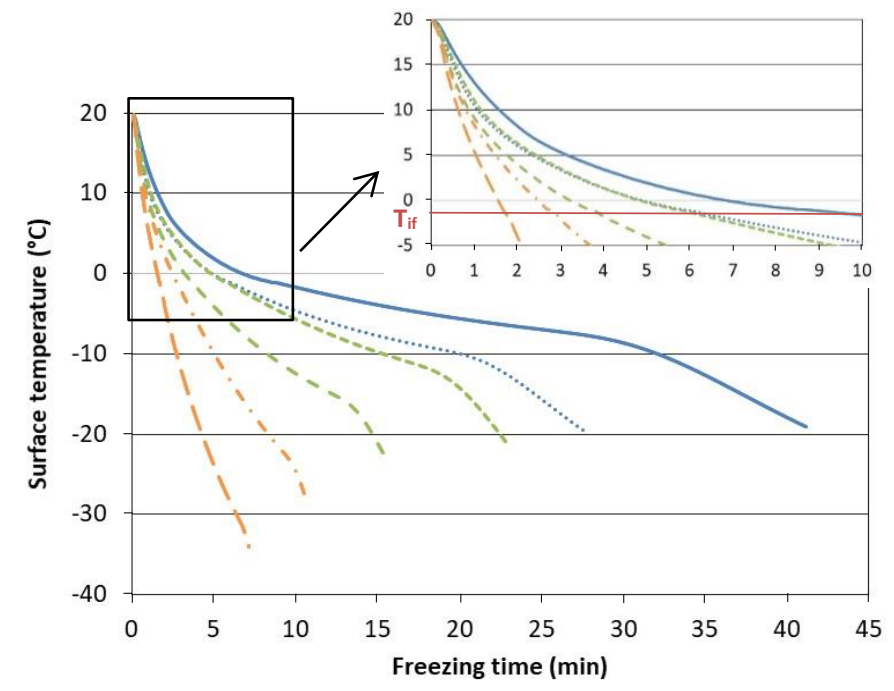

(b) Surface temperature

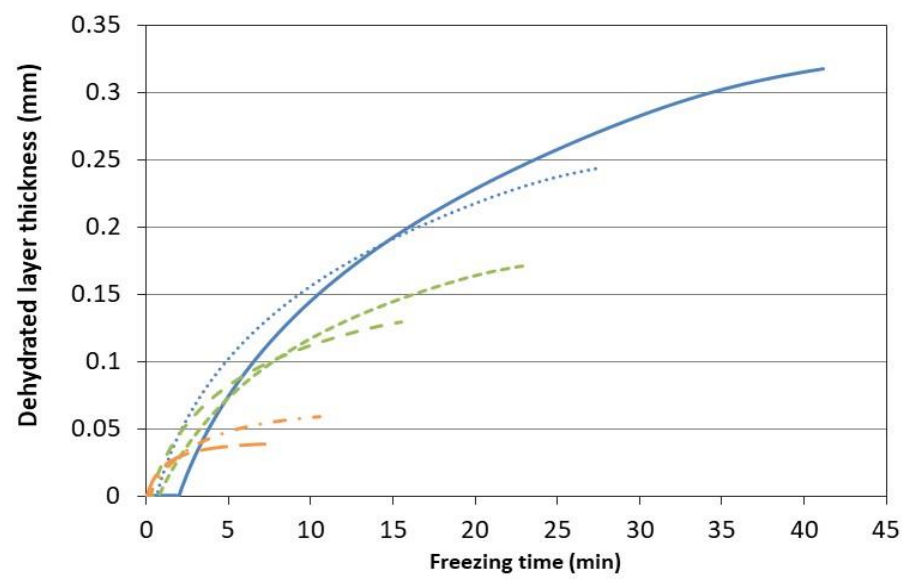

(d) Dehydrated layer

$$
\begin{aligned}
& -30^{\circ} \mathrm{C} / 3.9 \mathrm{~m} \mathrm{~s}^{-1}---50^{\circ} \mathrm{C} / 3.9 \mathrm{~m} \mathrm{~s}^{-1}-=-100^{\circ} \mathrm{C} / 3.9 \mathrm{~m} \mathrm{~s}^{-1} \\
& -30^{\circ} \mathrm{C} / 7.7 \mathrm{~m} \mathrm{~s}^{-1}---50^{\circ} \mathrm{C} / 7.7 \mathrm{~m} \mathrm{~s}^{-1}=-100^{\circ} \mathrm{C} / 7.7 \mathrm{~m} \mathrm{~s}^{-1}
\end{aligned}
$$

Figure 9: Core temperature (a), surface temperature (b), relative weight loss (c) and dehydrated layer thickness (d) according to freezing time for the 6 freezing operating conditions 


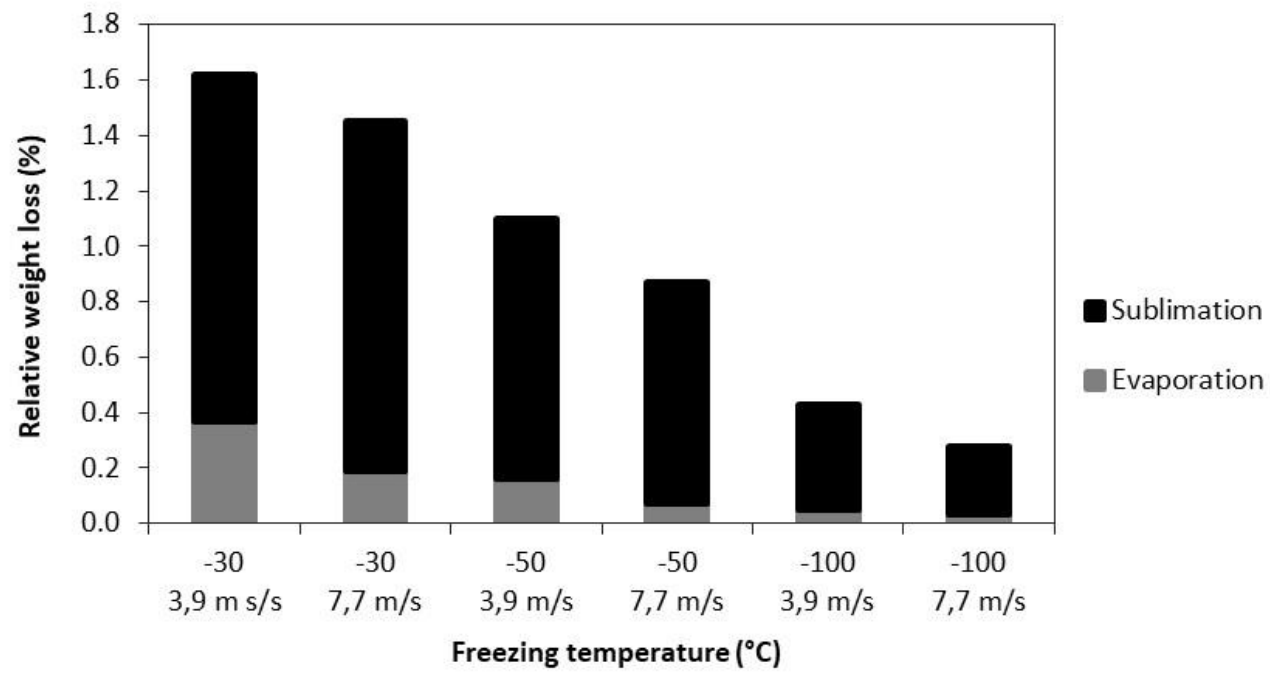

Figure 10: Predicted total relative weight loss (water evaporation + ice sublimation) according to freezing operating conditions for Tylose 
Table 1: Heat transfer coefficient (HTC) measurements.

Table 2: Estimation of heat and mass transfer parameters

Table 3 : Numerical freezing time ( $\mathrm{min}$ ) and relative weight loss (\%) according to the tortuosity value and the model used to estimate the thermal conductivity of the frozen product for the freezing condition $-30^{\circ} \mathrm{C}, 3.9 \mathrm{~m} \mathrm{~s}^{-1}$ 5

Table 4: Total relative weight losses and freezing times obtained experimentally (Exp.), predicted with the developed model (Model) and predicted with the simplified model (Simp. Model) 
Table 1: Heat transfer coefficient (HTC) measurements

\begin{tabular}{|c|c|c|c|c|}
\hline HTC $\left(\mathbf{W} \mathbf{~ m}^{-\mathbf{2}} \mathbf{K}^{-\mathbf{1}}\right)$ & \multicolumn{4}{|c|}{ Temperature set point $\left({ }^{\circ} \mathbf{C}\right)$} \\
\hline Velocity set point $\left(\mathbf{m ~ s}^{-\mathbf{1}}\right)$ & $\mathbf{1 5}$ & $\mathbf{- 3 0}$ & $\mathbf{- 5 0}$ & $\mathbf{- 1 0 0}$ \\
\hline 4.2 & $61 \pm 2$ & $67 \pm 6$ & $69 \pm 6$ & $83 \pm 6$ \\
\hline 6.6 & $89 \pm 4$ & $93 \pm 10$ & $97 \pm 10$ & $123 \pm 9$ \\
\hline 8.4 & $108 \pm 7$ & $112 \pm 14$ & $120 \pm 13$ & $159 \pm 13$ \\
\hline
\end{tabular}


Table 2: Estimation of heat and mass transfer parameters

\begin{tabular}{|c|c|}
\hline Parameters & Calculation \\
\hline $\begin{array}{c}\mathrm{Cp} \\
\text { Mass specific heat capacity } \\
\left(\mathrm{J} \mathrm{kg}^{-1}{ }^{\circ} \mathrm{C}^{-1}\right)\end{array}$ & $\begin{array}{l}\qquad \mathrm{Cp}=\sum_{\mathrm{j}}\left(\mathrm{X}_{\mathrm{j}} \mathrm{Cp}_{\mathrm{j}}\right) \\
\text { With } \mathrm{X}_{\mathrm{j}}=\frac{\mathrm{Y}_{\mathrm{j}}}{\sum_{\mathrm{j}} \mathrm{Y}_{\mathrm{j}}} \text { (Mass fraction of the component } \\
\text { j on a humid basis) }\end{array}$ \\
\hline $\begin{array}{c}\mathrm{Cpg}_{\mathrm{g}} \\
\text { Gas mass specific heat capacity } \\
\left(\mathrm{J} \mathrm{kg}^{-1}{ }^{\circ} \mathrm{C}^{-1}\right)\end{array}$ & $\begin{array}{c}\mathrm{Cp}_{\mathrm{g}}=-210^{-6} \mathrm{~T}_{\mathrm{m}}^{3}+0,0001 \mathrm{~T}_{\mathrm{m}}^{2}-0,0082 \mathrm{~T}_{\mathrm{m}} \\
+1041,4\end{array}$ \\
\hline $\begin{array}{c}\mathrm{C}_{\mathrm{vs}} \\
\text { Water vapor concentration in the } \\
\text { cold environment } \\
\left(\mathrm{kg} \mathrm{m}^{-3}\right)\end{array}$ & $C_{v s}=H R \frac{P_{s a t}\left(T_{s}\right) M_{w}}{R\left(T_{g}+273.15\right)}$ \\
\hline $\begin{array}{l}\text { Water vapor diffusivity } \\
\text { coefficient } \\
\left(\mathrm{m}^{2} \mathrm{~s}^{-1}\right)\end{array}$ & $D_{v}=1,4047 \times 10^{-9}(T+273,15)^{1,75}$ \\
\hline $\begin{array}{l}\mathrm{D}_{\mathrm{w}} \\
\text { Water diffusivity coefficient } \\
\left(\mathrm{m}^{2} \mathrm{~s}^{-1}\right)\end{array}$ & $\mathrm{D}_{\mathrm{w}}=0.662 \exp \left(\frac{-53600}{8.314(\mathrm{~T}+273.15)}\right)$ \\
\hline $\begin{array}{c}\mathrm{h}_{\mathrm{m}} \\
\text { External mass transfer coefficient } \\
\left(\mathrm{m} \mathrm{s}^{-1}\right)\end{array}$ & Lewis analogy: $h_{m}=\frac{h}{\rho_{g} C p_{g}}\left(\frac{\operatorname{Pr}}{S c}\right)^{2 / 3}$ \\
\hline $\begin{array}{l}\mathrm{k} \\
\text { Thermal conductivity } \\
\left(\mathrm{W} \mathrm{m} \mathrm{m}^{-1}{ }^{\circ} \mathrm{C}^{-1}\right)\end{array}$ & 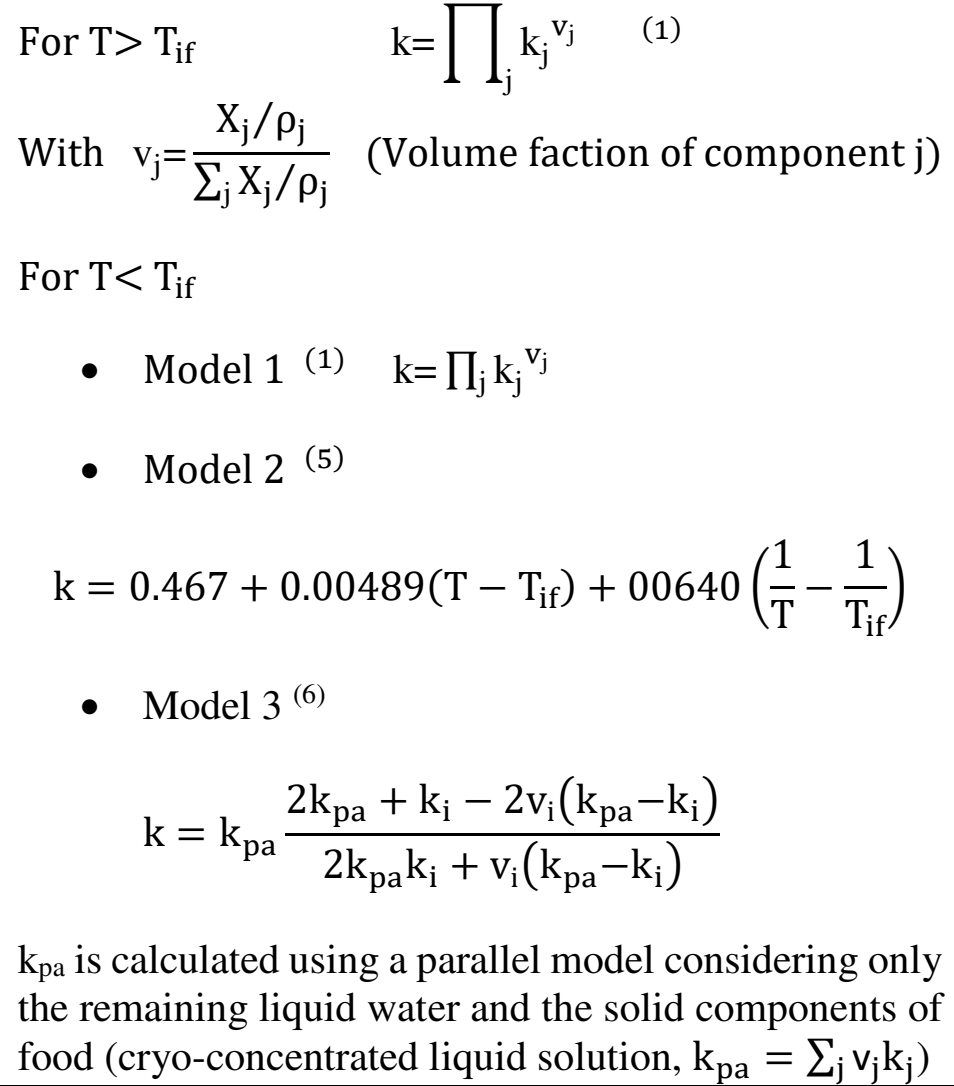 \\
\hline
\end{tabular}




\begin{tabular}{|c|c|}
\hline 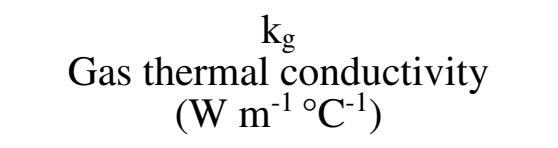 & $\begin{array}{c}\mathrm{k}_{\mathrm{g}}=810^{-11} \mathrm{~T}_{\mathrm{m}}^{3}-410^{-8} \mathrm{~T}_{\mathrm{m}}^{2}+710^{-5} \mathrm{~T}_{\mathrm{m}} \\
+0,024\end{array}$ \\
\hline $\begin{array}{c}\mathrm{T}_{\text {if }} \\
\text { Initial freezing temperature } \\
\left({ }^{\circ} \mathrm{C}\right)\end{array}$ & $\mathrm{T}_{\text {if }}=-1.0^{\circ} \mathrm{C}$ (Tylose) \\
\hline $\begin{array}{c}\varepsilon_{\mathrm{dl}} \\
\text { Porosity of the dehydrated layer }\end{array}$ & $\varepsilon_{\mathrm{dl}}=\frac{\mathrm{V}_{\text {pores }}}{\mathrm{V}_{\text {tot }}}=\frac{\mathrm{V}_{\text {(ice-bound water) }}}{\mathrm{V}_{\text {tot }}}$ \\
\hline $\begin{array}{c}\mu_{\mathrm{g}} \\
\text { Dynamic viscosity } \\
(\mathrm{Pa} \mathrm{s})\end{array}$ & $\mu_{\mathrm{g}}=-410^{-11} \mathrm{~T}_{\mathrm{m}}{ }^{2}+510^{-8} \mathrm{~T}_{\mathrm{m}}+210^{-5}$ \\
\hline $\begin{array}{c}\rho \\
\text { Density } \\
\left(\mathrm{kg} \mathrm{m}^{-3}\right)\end{array}$ & $\rho=\sum_{j}\left(\frac{X_{j}}{\rho_{j}}\right)^{-1}$ \\
\hline $\begin{array}{l}\rho_{\mathrm{g}} \\
\text { Gas Dênsity } \\
\left(\mathrm{kg} \mathrm{m}^{-3}\right)\end{array}$ & $\begin{array}{c}\rho_{\mathrm{g}}=-110^{-7} \mathrm{~T}_{\mathrm{m}}{ }^{3}+110^{-5} \mathrm{~T}_{\mathrm{m}}{ }^{2}-0,0045 \mathrm{~T}_{\mathrm{m}} \\
+1,2354\end{array}$ \\
\hline$\stackrel{\tau}{\text { Tortuosity }}$ & $\begin{array}{l}\tau_{\min }=1.0 \\
\tau_{\max }=2.0\end{array}$ \\
\hline
\end{tabular}
(1) Gulati and Datta (2013)
(2) Tocci and Mascheroni (1995)
(3) Anderson and Singh (2005)
(4) Erickson and Hung (1997)
(5) Pham and Willix (1990)
(6) Cogné et al. (2003)
(7) Campañone et al. (2001) 
Table 3 : Numerical freezing time (min) and relative weight loss $(\%)$ according to the tortuosity value and the model used to estimate the thermal conductivity of the frozen product for the freezing condition $-30^{\circ} \mathrm{C}, 3.9 \mathrm{~m} \mathrm{~s}^{-1}$

\begin{tabular}{|c|l|c|c|c|c|c|}
\hline Experimental freezing time $=\mathbf{4 3} \pm \mathbf{3}$ min & \multicolumn{5}{|c|}{ Tortuosity } \\
\cline { 3 - 7 } & $\mathbf{1 . 0}$ & $\mathbf{1 . 2 5}$ & $\mathbf{1 . 5}$ & $\mathbf{1 . 7 5}$ & $\mathbf{2 . 0}$ \\
\hline \multirow{3}{*}{$\begin{array}{c}\text { Thermal conductivity of the } \\
\text { frozen product }\end{array}$} & Model 1 & 39.9 & 40.2 & 40.5 & 40.7 & 40.8 \\
\cline { 2 - 7 } & Model 2 & 40.6 & 40.9 & 41.1 & $\mathbf{4 1 . 3}$ & 41.5 \\
\cline { 2 - 7 } & Model 3 & 40.3 & 40.6 & 40.8 & 41.0 & 41.2 \\
\hline
\end{tabular}

\begin{tabular}{|c|l|c|c|c|c|c|}
\hline Experimental weight loss $=1 \mathbf{1 . 6 1} \pm \mathbf{0 . 0 5} \%$ & \multicolumn{5}{|c|}{ Tortuosity $\boldsymbol{\tau}$} \\
\cline { 3 - 7 } & Model 1 & 1.0 & $\mathbf{1 . 2 5}$ & $\mathbf{1 . 5}$ & $\mathbf{1 . 7 5}$ & $\mathbf{2 . 0}$ \\
\hline \multirow{3}{*}{$\begin{array}{c}\text { Thermal conductivity of the } \\
\text { frozen product }\end{array}$} & Model 2 & 1.87 & 1.77 & 1.69 & 1.63 & 1.57 \\
\cline { 2 - 7 } & Model 3 & 1.87 & 1.77 & 1.69 & 1.62 & 1.57 \\
\hline
\end{tabular}


Table 4: Total relative weight losses and freezing times obtained experimentally (Exp.), predicted with the developed model (Model) and predicted with the simplified model (Simp. Model)

\begin{tabular}{|c|c|c|c|c|c|c|c|}
\hline \multirow[b]{2}{*}{$\begin{array}{c}\text { Temperature } \\
\left(\mathbf{T}_{\mathbf{g}},{ }^{\circ} \mathbf{C}\right)\end{array}$} & \multirow[b]{2}{*}{$\begin{array}{c}\text { Heat transfer } \\
\text { coefficient } \\
\left(\mathbf{h}, \mathbf{W} \mathbf{m}^{-2} \mathbf{K}^{-1}\right)\end{array}$} & \multicolumn{3}{|c|}{ Relative weight loss (\%) } & \multicolumn{3}{|c|}{ Freezing time (min) } \\
\hline & & Exp. & Model & $\begin{array}{l}\text { Simp. } \\
\text { model }\end{array}$ & Exp. & Model & $\begin{array}{l}\text { Simp. } \\
\text { model }\end{array}$ \\
\hline \multirow{2}{*}{-30} & 55 & $1.61 \pm 0.05$ & 1.62 & 2.65 & $43 \pm 3$ & 41.3 & 37.1 \\
\hline & 94 & $1.56 \pm 0.07$ & 1.45 & 2.81 & $29 \pm 1$ & 27.7 & 25.2 \\
\hline \multirow{2}{*}{-50} & 58 & $0.98 \pm 0.11$ & 1.10 & 1.57 & $30 \pm 2$ & 22.9 & 22.2 \\
\hline & 99 & $0.85 \pm 0.15$ & 0.87 & 1.32 & $21 \pm 1$ & 15.5 & 15.1 \\
\hline \multirow{2}{*}{-100} & 67 & $0.71 \pm 0.10$ & 0.43 & 0.50 & $14 \pm 1$ & 10.6 & 10.6 \\
\hline & 116 & $0.46 \pm 0.03$ & 0.28 & 0.34 & $11 \pm 1$ & 7.2 & 7.2 \\
\hline
\end{tabular}

